\title{
Targeting Exocytosis: Ins and Outs of the Modulation of Quantal Dopamine Release
}

\author{
Remco H.S. Westerink ${ }^{*}$
}

Center for NeuroScience (CNS), Swammerdam Institute for Life Sciences(SILS), University of Amsterdam, Kruislaan 320, NL-1098 SM Amsterdam, The Netherlands

Cellular and Molecular Toxicology, Institute for Risk Assessment Sciences, Utrecht University, P.O.Box 80.176, 3508

TD Utrecht, The Netherlands

\begin{abstract}
Dopaminergic neurotransmission is mediated by the vesicular release of dopamine (DA), i.e. DA exocytosis. DA exocytosis and its modulation are generally believed to affect neuronal communication, development, maintenance and survival, and contribute to extracellular DA levels in the brain. As a result, DA exocytosis likely plays an important role in several neurological and psychiatric disorders, like Parkinson's disease (PD) and schizophrenia. As exocytosis is part of a sophisticated ensemble of processes, it can be modulated at different levels, including DA synthesis, uptake and vesicular transport as well as $\mathrm{Ca}^{2+}$-homeostasis and exocytotic proteins. Nonetheless, to be effective, modulation of exocytosis should result in functional changes, which are reflected by changes in release frequency, vesicle contents, and the time course of the exocytotic event. As will be shown in this review, functional changes in DA exocytosis can be produced by e.g. pharmacological/drug treatment, feedback mechanisms and up/down-regulation of exocytosis-related proteins. Moreover, the mode of DA exocytosis, i.e. classical full fusion or kiss-and-run exocytosis, could also serve as a potential target for functional modulation of dopaminergic neurotransmission. Since the onset and progression of neurological and psychiatric disorders often show a strong correlation with changes in brain DA levels, DA synthesis, transport or uptake, the findings described in this review highlight the importance of the modulation of (the mode of) DA exocytosis for normal progression of dopaminergic neurotransmission and the potential of exocytotic processes as drug targets.
\end{abstract}

Keywords: Vesicular catecholamine release, exocytosis, amperometry, neurotransmission, presynaptic modulation, dopamine autoreceptors, calcium homeostasis.

\section{INTRODUCTION}

Dopaminergic neurotransmission is critical for normal motor-, motivational- and reward-related functions of the nervous system. Communication between neurons and neuroendocrine cells is generally initiated by exocytosis, i.e. the fusion of a neurotransmitter-filled vesicle with the presynaptic cell membrane. DA, or more generally catecholamines, can be stored in small or large dense-core vesicles (SDCVs or LDCVs) as well as in synaptic vesicles $(\mathrm{SV})$, which differ in dimensions and the amount of stored neurotransmitter. Following vesicle fusion, the released neurotransmitters diffuse to postsynaptic receptors to elicit a postsynaptic response. The strength of the presynaptic signal is determined by the number of vesicles that fused, the amount of neurotransmitter released per vesicle and the timecourse of this release event. Exocytosis is part of a complex ensemble of processes, known as the vesicle cycle (1; Fig. 1). The vesicle cycle starts in the cell cytoplasm, where lipid vesicles are filled with neurotransmitters. These filled vesicles are translocated to the cell membrane in order to become docked and primed. Subsequent release of the vesicle content, through fusion of the vesicle and cell

*Address correspondence to this author at the Cellular and Molecular Toxicology, Institute for Risk Assessment Sciences, Utrecht University, P.O. Box 80.176, 3508 TD Utrecht, The Netherlands; E-mail: r.westerink@iras.uu.nl membranes, is triggered by an increase in the intracellular $\mathrm{Ca}^{2+}$ concentration $\left(\left[\mathrm{Ca}^{2+}\right]_{i}\right)$. Exocytosis is followed by endocytosis, which enables efficient recycling of released vesicles and occurs in two forms: slow, clathrin-mediated endocytosis following full fusion and a rapid retrieval of transiently fused vesicles during kiss-and-run exocytosis. Irrespective of the type of endocytosis, the retrieved lipid vesicles are re-filled with neurotransmitter molecules for successive rounds of exocytosis. The process of endocytosis closes the vesicle cycle and consequently affects the availability of vesicles. Moreover, the mode of exocytosis, i.e. full fusion or kiss-and-run exocytosis, may be an essential regulator of neurotransmission as it can affect the release frequency as well as the time course of the release event.

In the case of dopaminergic neurotransmission, signaling is not restricted to point-to-point synaptic contacts. The extrasynaptic localization of DA receptors, as well as the appearance of DA signals in extracellular space of striatum following stimulation or motivational and reward-associated behaviors, implies that dopaminergic neurotransmission relies to a certain extent on volume transmission. Volume transmission requires synaptic spillover of released DA to reach distant target cells through extracellular diffusion [2]. Both, direct point-to-point synaptic transmission and volume transmission strongly depend on DA exocytosis as well as on DA uptake and DA receptors. Not surprisingly, the role of DA receptors and transporters, the excitability of 


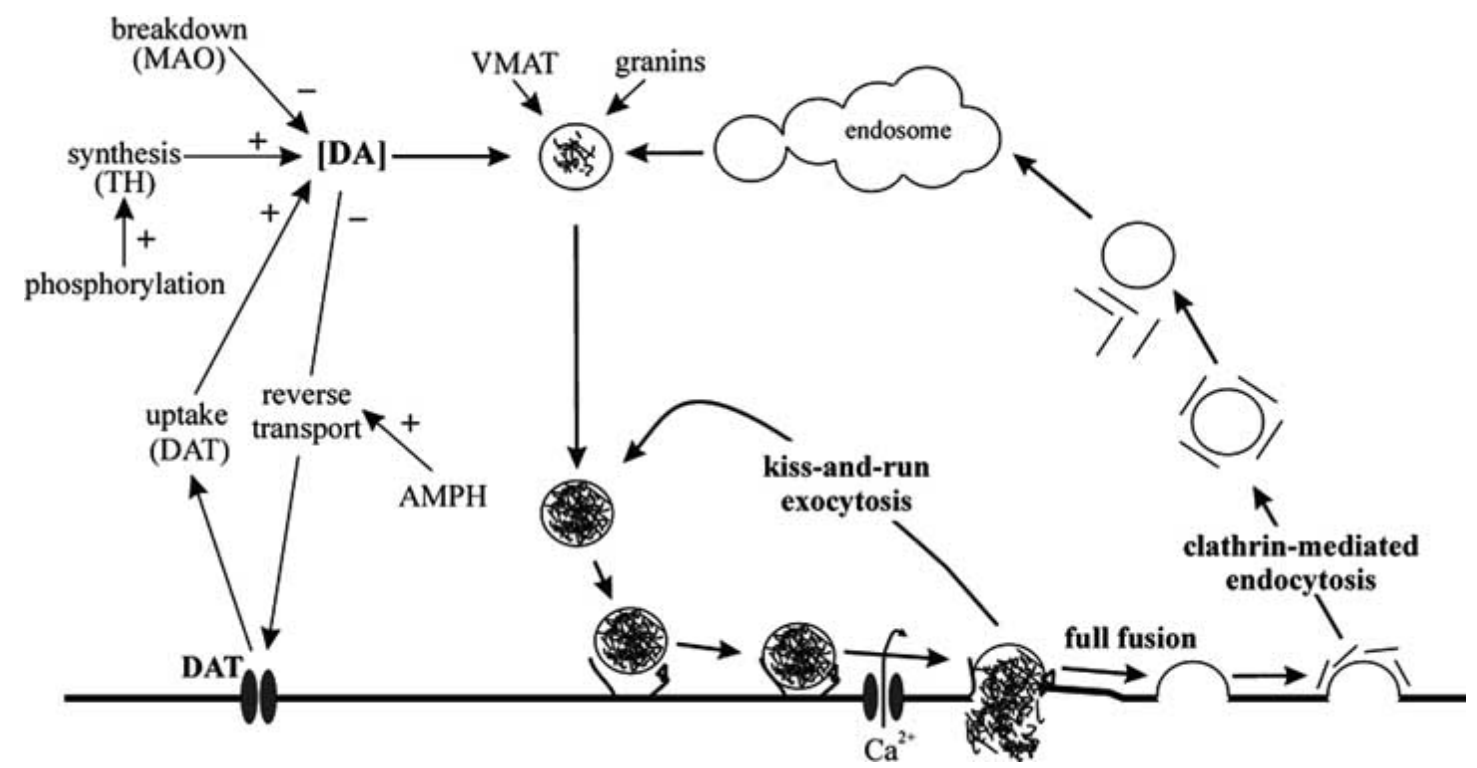

Fig. (1). DA is stored in vesicles, which translocate to the cell membrane to become docked and primed. The degree of vesicle filling depends on the availability of cytosolic DA, which depends on the balance between uptake (DAT), synthesis (TH) and breakdown (MAO), as well as on the vesicular transport (VMAT) and intravesicular storage capacity (granins, in case of dense-core vesicles). Fusion of primed vesicles and release of vesicle contents is triggered by an increase in $\left[\mathrm{Ca}^{2+}\right]_{\mathrm{i}}$. Following transient fusion, vesicles are rapidly retrieved through so-called kiss-and-run exocytosis. Alternatively, vesicles undergo full fusion, followed by slow clathrin-mediated endocytosis. In both cases, the retrieved vesicles are re-filled for subsequent rounds of exocytosis.

dopaminergic neurons and the extracellular DA levels in the brain, especially in relation to the diseased state, has received ample attention [see other chapters in this theme issue].

The modulation of quantal DA release is rapidly proving to be imperative for a further understanding of dopaminergic neurotransmission. However, as this field of research is relatively new, information regarding the modulation of DA exocytosis is often derived from neuroendocrine cells that release catecholamines. Taking the results obtained from neuroendocrine cells into account as well, as is done in this review, it is becoming increasingly clear that changing one or more steps in the vesicle cycle allows for modulation of the release frequency, vesicle contents, and the time course of the exocytotic event. Moreover, the vesicular DA content varies to a considerable extent and vesicular DA release is far from being a simple 'all or none' process in which a fixed amount of neurotransmitter is released. As will be shown below for distinct steps of the vesicle cycle, distortion of even one single interaction by drugs, toxicants or degenerative processes is sufficient to greatly affect what is in the vesicle and how, how much and how often the contents of the vesicle is released, and how this can relate to a severe impairment of dopaminergic neurotransmission.

\section{DETECTION OF EXOCYTOSIS}

As exocytosis is an extremely rapid process, sensitive techniques with high temporal resolution are required to measure exocytosis and its modulation in detail [3]. A classic technique to measure exocytosis is to postsynaptically measure the response evoked by the presynaptic release of neurotransmitters using electrophysiological techniques [4]. However, this method is not very suitable for quantitative studies investigating the presynaptic modulation of neurotransmitter release, since many drugs are able to affect the presynaptic as well as the postsynaptic response. Moreover, the vesicular release of catecholamines does not evoke postsynaptic quantal responses.

As an alternative, the net result of exocytosis and endocytosis can be quantified by measuring the capacitance of the presynaptic cell membrane [5]. When used in the socalled cell-attached mode, the sensitivity of this technique is sufficient to resolve single vesicle fusions, even in case of vesicles with the dimensions of SVs, and allows for determination of the vesicle size and fusion pore expansion [6-8]. However, the amount of neurotransmitter released per vesicle cannot be measured with this technique. Optical techniques, including total internal reflection fluorescence microscopy, preclude determination of amount of neurotransmitter released per vesicle as well, though they are applicable to distinguish between full fusion and kiss-andrun exocytosis [9-11]. In case of presynaptic dopaminergic neurotransmission, most studies rely on electrochemical techniques, like amperometry and voltammetry.

By rapid oxidation of released neurotransmitters at a carbon fiber microelectrode, amperometry and patchamperometry allow for the detection of quantal catecholamine and serotonin release, with sufficient temporal resolution and sensitivity to determine the frequency of vesicular release, the amount of catecholamine or serotonin released per vesicle, the kinetics of individual release events and even the kinetics of fusion pore formation and expansion $[6,7,12]$. Amperometry is non-invasive and applicable in vitro on single cells in culture or in brain slices, as well as in vivo, though in the latter case, single vesicle resolution is 
lost. In brain/brain slices cyclic voltammetry is often used to measure DA release without single vesicle resolution [Heien and Wightman, this issue]. Using amperometry and voltammetry, vesicular catecholamine and serotonin release has been measured from a large variety of preparations, including mast cells, neuroendocrine chromaffin and PC12 cells and several types of serotonergic and dopaminergic neurons [for review see 3, for a review on the statistical approaches on quantal neurotransmitter secretion see 13]. These, and numerous other studies, provided a large part of the fundaments of our current knowledge on the modulation of DA exocytosis and will provide additional important insights in the future.

\section{AVAILABILITY OF CYTOSOLIC DA FOR VESICLE FILLING}

As mentioned above, the vesicle cycle starts with vesicle filling. The degree of vesicle filling, and consequently the amount of DA that can be released per vesicle during vesicle fusion, depends largely on the availability of cytosolic DA (for review see 13; Fig. 1). As will be shown below, the availability of cytosolic DA is critical for proper neurotransmission and depends on the strictly regulated balance between DA uptake, synthesis and breakdown.

\section{DA Uptake}

DA uptake is achieved by the DA membrane transporter (DAT), the major role of which is the clearance of released DA from the extracellular space, and its dysfunction is associated with several dopaminergic disorders [14, Sotnikova et al. this theme issue]. In addition to clearing DA from the extracellular space, DAT recycles released DA making it available again for vesicle filling. Consequently, DAT reduces the need for newly synthesized DA. DAT inhibitors, like nomifensine and cocaine, decrease DA uptake and increase extracellular DA levels. However, in genetically-altered mice lacking DAT the amplitude of evoked DA release in both striatum and nucleus accumbens (NAcc) is lower than in wild-type mice, though the lifetime of extracellular DA is, of course, prolonged $[15,16]$. Additionally, in DAT-KO mice, DA release [16] and the tissue content of DA [15] are much more dependent on DA synthesis than in wild-type mice. These observations point out the importance of DAT to replenish intracellular stores of DA and for sustained DA release. Moreover, a recent amperometric study using DAT overexpressing neuroendocrine PC12 cells indicated that DAT affects the amount of DA released per vesicle as well as the release frequency by increasing DA availability [17]. The combined results demonstrate that DAT-mediated DA uptake can affect the release frequency as well as the amount of DA released per vesicle, suggesting that the observed decrease in evoked DA release in striatum and NAcc of DAT-KO mice is the result of a reduction in the release frequency in combination with a reduction of the amount of DA released per fusion event. It should be noted that the prolonged lifetime of extracellular DA in DAT-KO mice could also reduce the amount of DA stored and released per vesicle due to ongoing D2 autoreceptor activation (see below).

Additionally, substrates of DAT, such as DA and amphetamine (AMPH), elicit inward, $\mathrm{Na}^{+}$-dependent currents in dopaminergic neurons, which may modulate neuronal excitability and consequently can affect the release frequency [18]. Moreover, DAT can enhance DA release through reverse transport. In particular AMPH is capable of inducing reverse transport of DA, which appears to be voltage-dependent [19] and under control of $\left[\mathrm{Ca}^{2+}\right]_{i}[20]$ and protein kinase $\mathrm{C}$ (PKC) activity [21]. Incubation of mouse striatal slices [15], Planorbis giant DA neurons or PC12 cells [22] with AMPH reduces the net DA uptake rate and increases extracellular DA levels due to DA efflux through the DAT.

\section{DA Synthesis}

DA can be synthesized in the cell by conversion of tyrosine to dihydroxyphenylalanine (L-DOPA), by the cytosolic enzyme tyrosine hydroxylase $(\mathrm{TH})$, and subsequent conversion to DA by aromatic amino acid decarboxylase $[23,24]$. As the conversion of tyrosine to L-DOPA by TH is the rate-limiting step in DA synthesis, TH plays an important role in determining the availability of cytosolic DA for vesicle filling. The activity of $\mathrm{TH}$ is increased by phosphorylation and it is known for many years that various treatments, including high $\mathrm{K}^{+}$, caffeine-induced mobilization of $\mathrm{Ca}^{2+}$ from internal $\mathrm{Ca}^{2+}$ stores and activation of cAMPdependent protein kinase A (PKA), PKC and extracellular signal-regulated kinase (ERK), increase DA synthesis [2528]. Furthermore, a number of neurotrophic and neuromodulatory drugs, including glial cell-line derived neurotrophic factor (GDNF) [28], estrogens [29] and 3,4methylenedioxymethamphetamine (MDMA, "ecstasy") [30] increase TH phosphorylation and DA synthesis, at least partly by activation of one or more of the above-mentioned kinases. On the other hand, apomorphine [31] and the nigrostriatal neurotoxin 1-methyl-4-phenyl-1,2,3,6tetrahydropyridine (MPTP) [32] inhibit DA synthesis. Application of the D2-like agonist quinpirole reduces $\mathrm{TH}$ phosphorylation and DA synthesis as well [33], whereas D2 antagonists increase TH activity and DA synthesis [34]. The effects of D2 antagonists on $\mathrm{TH}$ phosphorylation are abolished in D2 receptor-null mutant mice and prevented by blockade of ERK 1 and 2 [34], indicating the involvement of ERK1/2 in D2 receptor mediated regulation of $\mathrm{TH}$ activity and DA synthesis.

Following the introduction of single cell amperometry, it was possible to directly demonstrate the effects of modulation of DA availability on vesicle filling. Bypassing TH by application of exogenous L-DOPA significantly increased cytosolic DA levels in chromaffin cells [35] and, consequently, the amount of DA released per vesicle in chromaffin cells [36], PC12 cells [37], as well as in ventral midbrain neurons [38]. Moreover, amperometric recordings in PC12 cells exposed to quinpirole, which inhibits $\mathrm{TH}$ activity by approximately $50 \%$, reduced vesicle contents by approximately $50 \%$. This reduction in vesicle contents could be blocked by the D2 antagonist sulpiride [39], demonstrating that the above mentioned relation between D2 activation and DA availability indeed affects vesicle contents.

The availability of cytosolic DA appears critical in a number of neurological disorders. In line with this, TH levels are significantly elevated in post-mortem basal ganglia of 
schizophrenic patients [40]. Moreover, mice lacking THexpression in dopaminergic neurons displayed multiple behavioral abnormalities [41]. PD, which is characterized by reduced striatal DA levels after a marked loss of substantia nigra (SN) dopaminergic neurons, is often treated by application of exogenous L-DOPA [42], highlighting the importance of cytosolic DA levels. Alpha-synuclein (alphaSyn) is a small presynaptic nerve terminal protein implicated in the modulation of $\mathrm{TH}$ as well as in PD. In PD, soluble alpha-Syn levels are diminished in SN dopaminergic neurons, both by reduced expression and by alpha-Syn aggregation as Lewy bodies. Reduced alpha-Syn levels result in increased DA synthesis through upregulation of $\mathrm{TH}$, reduced vesicular DA storage and increased DAT-mediated DA uptake, and consequently in excess cytosolic DA. The excess cytosolic DA is oxidized to the quinones and reactive oxygen species that likely account for the observed neurodegeneration [for review see 43]. The importance of alpha-Syn is further demonstrated in alpha-Syn null mutant mice, which are viable and fertile but exhibit altered DA release, a reduction in striatal DA and an attenuation of DAdependent locomotor response to AMPH [44]. Moreover, PC12 cells expressing mutant alpha-Syn, but not wild-type alpha-Syn, display a loss of catecholamine-containing LDCV and of depolarization-induced catecholamine release [45]. Chromaffin and PC12 cells overexpressing alpha-Syn display a reduced vesicle release frequency, though vesicle contents appears unaffected (D. Sulzer, personal communications). Finally, it was suggested that alpha-Syn, at least at hippocampal nerve terminals, could regulate SV mobilization [46]. Thus, alpha-Syn is likely to affect dopaminergic neurotransmission by affecting DA synthesis, transport and storage, though effects on the formation and mobilization of vesicles can contribute as well.

\section{DA Breakdown}

Intracellular DA that is not stored in vesicles is metabolized by one of two types of monoamine oxidase (MAO-A or MAO-B), which function both intracellularly and extracellularly $[23,24]$. Therefore, changes in MAO could directly affect the availability of cytosolic DA for vesicle filling. The physiological importance of MAO for dopaminergic neurotransmission is underlined by the fact that MAO inhibitors have long been used as anti-depressant drugs and for the treatment of PD [47]. Furthermore, MAOdeficiency or inhibition of MAO has been linked to hyperaggressive and anxiety behavior [48,49] and increased brain DA levels [49]. However, to date there are no reports of altered vesicle filling in relation to changes in MAO. This could indicate that the cytosolic DA concentration is strictly maintained at a defined level [see e.g. 35], which requires a tight regulation of both DA synthesis and metabolism. Future studies using transgenic MAO-deficient mice or MAO inhibitors will have to clarify whether vesicle filling and subsequent DA release can be modulated directly by DA metabolism and whether this provides a novel drug target for the modulation of vesicular DA release.

\section{VESICULAR DA TRANSPORT AND STORAGE}

In addition to the availability of cytosolic DA, vesicle filling is determined by the vesicular $\mathrm{pH}$, the efficiency of the vesicular monoamine transporter (VMAT) and the storage capacity of the vesicles [for review see 13]. As will be shown below, neurological disorders are often accompanied by changes in vesicular transport and storage, which can directly or indirectly affect the amount of DA released per vesicle as well as the release frequency.

\section{Vesicular Monoamine Transporter}

Cytosolic DA is concentrated in vesicles by specific neurotransmitter transporters on the vesicle membrane, VMAT-1 and VMAT-2 [50,51]. Vesicular DA uptake is ATP dependent and abolished by reserpine, tetrabenazine, and by inhibition of the vacuolar $\mathrm{H}^{+}$-ATPase or by disruption of the vesicular proton-gradient. The expression of VMAT is enhanced by depolarization-induced $\mathrm{Ca}^{2+}$ entry, elevation of the intracellular cyclic AMP concentration or activation of PKC [50,51]. The markedly reduced expression levels of VMAT-2 in SN and NAcc dopaminergic neurons in patients with PD [52] and in cocaine users [53], as well as the poor viability of homozygous VMAT-2 KO mice [54] indicate the critical involvement of VMAT in normal dopaminergic neurotransmission. It is noteworthy that VMAT appears to protect catecholamine-containing neurons from MPTPinduced degeneration by sequestration of the toxin within vesicles [55,56], thereby possibly preventing oxidative damage. In addition, heterozygous VMAT-2 KOs, which display VMAT-2 levels one-half that of wild-type values, contain substantially lower monoamine levels in brain, are more susceptible to the neurotoxic effects of MPTP, exhibit reduced extracellular striatal DA levels, and display reduced depolarization-evoked and AMPH-evoked DA release [54]. This suggests that VMAT-2 expression regulates monoamine storage and release, and that a reduction in VMAT-2 expression could be reflected in a reduced vesicle contents and possibly a reduced release frequency as well.

In neuroendocrine PC12 cells, vesicular monoamine transport is down-regulated by the protein phosphatase inhibitor okadaic acid, whereas the PKA inhibitor K252a increases vesicular amine transport [57]. As a weak base and a substrate for VMAT, AMPH, as well as other weak bases, reduce the vesicular $\mathrm{pH}$ gradients. Consequently, AMPH induces the redistribution of DA from vesicles to cytosol, which in turn increases cytosolic DA levels and promotes DAT-mediated reverse transport of DA [22,58]. Using intracellular patch electrochemistry to directly measure the levels of cytosolic oxidizable molecules in single chromaffin cells, it was demonstrated that AMPH indeed increases the cytosolic catecholamine concentration [35]. Furthermore, exposure to methamphetamine (METH) and MDMA, rapidly decreases vesicular DA uptake in striatum [59,60], suggesting that amphetamines in general rapidly decrease vesicular monoamine transport in dopaminergic neurons. Surprisingly, most DAT inhibitors, including methylphenidate and cocaine, rapidly increase vesicular DA uptake in isolated striatal SVs and reverse the METHinduced decrease in vesicular DA uptake and in vesicular DA content $[61,62]$. The non-competitive NMDA receptor antagonist phencyclidine rapidly increases vesicular DA uptake as well [63]. As with DA synthesis, there appears to be a feedback mechanism mediated primarily by $\mathrm{D} 2$ receptors, as the effects of methylphenidate, cocaine and phencyclidine are attenuated by the $\mathrm{D} 2$ receptor antagonist 
eticlopride [61-63]. Similar to the effects of cocaine, treatment with the D2 agonist quinpirole [61] or apomorphine [64] increases vesicular DA uptake. The effects of apomorphine on vesicular DA uptake are blocked by the D2 receptor antagonist eticlopride as well [64]. Taken together, these data indicate the involvement of a D2 receptor-mediated pathway for the modulation of VMAT and, additionally, that D2 receptor activation, per se, is sufficient to increase vesicular DA uptake.

Using amperometry it was shown that the VMAT inhibitor reserpine decreases the amount of catecholamines released per exocytotic event in neuroendocrine PC12 and chromaffin cells $[65,66]$. These changes in vesicular catecholamine content correlate directly with changes in vesicle volume, indicating that the concentration of catecholamines within the vesicles remains relatively constant [66,67]. In axonal varicosities of midbrain DA neurons, which contain predominantly SVs, quantal DA release is completely abolished by reserpine [38], indicating that the amount of DA released per vesicle has fallen below detection limits, or that the varicosities no longer exhibit exocytosis. Moreover, impulse-dependent DA release in striatal slices, measured using fast cyclic voltammetry, is strongly reduced in transgenic mice with approximately $95 \%$ reduced expression of the VMAT-2 gene, indicating smaller vesicular DA stores [68]. On the other hand, overexpression of VMAT-2 in axonal varicosities of midbrain DA neurons increases both vesicle contents and release frequency, consistent with the recruitment of SVs that do not normally release DA [69] or normally remain undetected because of the very small amounts of DA released per vesicle. VMAT-2 expression in PC12 cells increases vesicle contents as well, though not the release frequency [69]. In line with enhanced depolarization-induced VMAT expression, stimulation of chromaffin cells with high $\mathrm{K}^{+}$increases the internal acidity of chromaffin vesicles. This stimulation-induced vesicle acidification is $\mathrm{Ca}^{2+}$-dependent and blocked by inhibition of the vacuolar $\mathrm{H}^{+}$-ATPase using bafilomycin. Coinciding with acidification, high $\mathrm{K}^{+}$stimulation increases the average vesicle volume and vesicle contents, whereas inhibition of vacuolar $\mathrm{H}^{+}$-ATPase decreases vesicle contents [36]. Though disruption of vesicular stores reduces the amount of neurotransmitter released per vesicle, application of a weak base (methylamine, AMPH, or tyramine) or of the VMAT inhibitor reserpine can induce catecholamine exocytosis in chromaffin cells. This is due to the fact that LDCVs normally contain large amounts of $\mathrm{Ca}^{2+}$ (see below), which is liberated together with the stored catecholamines from the vesicles upon disruption of vesicular stores. Apparently, AMPH and methylamine can disrupt vesicular stores to a sufficient degree that both catecholamines and $\mathrm{Ca}^{2+}$ can escape vesicles, resulting in an increase in cytosolic catecholamines as well as an increase in $\left[\mathrm{Ca}^{2+}\right]_{\mathrm{i}}$ sufficiently large to trigger exocytosis $[65,70]$. The combined results demonstrate that vesicular transporters limit the rate of transmitter accumulation in secretory vesicles and that vesicle contents is increased when the driving force for their uptake is enhanced. Moreover, disruption of vesicular stores reduces the amount of DA released per vesicle, though vesicular $\mathrm{Ca}^{2+}$, liberated by this disruption, can increase the frequency of DA exocytosis.

\section{Intravesicular Storage}

Neurotransmitters are stored in SVs, SDCVs or LDCVs at concentrations that far exceed the cytosolic neurotransmitter concentration. To do so, an effective storage mechanism is required. In case of DA-containing SDCVs or LDCVs, storage is achieved by binding of DA to an intravesicular matrix, which keeps the osmolarity low and thus prevents excessive swelling of the vesicles. The intravesicular storage matrix is made up of granins, i.e. chromogranins $\mathrm{A}(\mathrm{CgA})$ and $\mathrm{B}(\mathrm{CgB})$ and secretogranins (Table 1), which can be co-released with catecholamines during exocytosis from sympathetic nerve terminals and neuroendocrine cells [71]. CgA plays a crucial role in the regulation of the formation of LDCVs, as down-regulation of $\mathrm{CgA}$ expression in neuroendocrine PC12 cells led to profound loss of secretory granule proteins and LDCVs, and impairment of regulated secretion. In CgA-deficient PC12 cells the regulated secretory phenotype could be rescued by transfection with $\mathrm{CgA}$ [72]. Thus, $\mathrm{CgA}$ appears to be an "on/off" switch and is a required factor for the formation of LDCVs in neuroendocrine cells. It remains to be established whether this applies to SDCVs in dopaminergic neurons as well.

Additionally, granins tend to bind large amounts of $\mathrm{Ca}^{2+}$, allowing for the storage of large amounts of $\mathrm{Ca}^{2+}$ in LDCVs [73]. As $\mathrm{CgA}$ and $\mathrm{CgB}$ are coupled to and interact with inositol-1,4,5-triphosphate (IP3) receptors [74], which are present on LDCVs and can function as $\mathrm{Ca}^{2+}$ channels, LDCVs are believed to play an important role in regulation of the $\left[\mathrm{Ca}^{2+}\right]_{\mathrm{i}}[73,75]$. Consequently, granins may also be a target for modulation of the frequency of quantal catecholamine release, as the liberation of stored vesicular $\mathrm{Ca}^{2+}$ could play an important role in the catalysis of exocytosis $[65,70]$. Furthermore, granins and their cleavage products can act as autocrine feedback factors [71]. CgA, or one of its cleavage products, potently inhibits depolarizationinduced DA release from striatal slices [76].

The effects of the proteolytic cleavage products of granins on catecholamine release are summarized in Table $\mathbf{1}$, with the $\mathrm{CgA}$ and $\mathrm{CgB}$ proteolytic cleavage products inhibiting secretion in neuroendocrine cells and noradrenergic neurites [77-82]. On the other hand, secretogranin-derived secretoneurin stimulates the release of DA from nigrostriatal neurons [83]. Thus, granins and derived cleavage products provide an autocrine feedback mechanism controlling the frequency of catecholamine release within neuroendocrine cells and neurons. Considering the wide distribution [84,85] and above described properties of granins, it is not surprising that granin levels are often altered in the diseased brain. $\mathrm{CgA}$ levels in the cerebrospinal fluid are reduced in patients with PD, which may be a useful diagnostic finding [84]. Furthermore, $\mathrm{CgA}$ accumulates in the senile and pre-amyloid plaques of Alzheimer's disease, in PD-associated Lewy bodies in the SN, and in the swollen neurons of Pick's disease [86,87], whereas patients with schizophrenia display reduced granin levels in the prefrontal cortex [88].

Summarizing, modulation of the vesicular protongradient, the vesicular neurotransmitter transporter or the availability of storage molecules affects the amount of vesicular neurotransmitter uptake and storage, and eventually 
Table 1.

\begin{tabular}{|c|c|c|c|c|}
\hline Prohormone & Active peptide & Effect on exocytosis & Mechanism & Ref. \\
\hline \hline & pancreastin & $\downarrow$ & phospholipase activation & [79] \\
\hline $\mathrm{CgA}$ & parastatin & $\downarrow$ & phospholipase activation & {$[77]$} \\
\hline & vasostatin & $\downarrow$ & inhibition of L-type Ca ${ }^{2+}$ channels & {$[$ nicotinic cholinergic antagonist } \\
\hline $\mathrm{CgB}$ & chromostatin & $\downarrow$ & & {$[81,82]$} \\
& catestatin & $\downarrow$ & G protein-coupled receptor cascade & {$[83]$} \\
\hline
\end{tabular}

Granins serve as prohormones (first column) for a number of proteolytic cleavage products (second column). These cleavage products exert modulatory effects on exocytosis (third column) through the mechanisms indicated (fourth column).

the amount of neurotransmitter secreted during vesicle fusion. In combination with the granin-mediated autocrine feedback, this is likely of critical importance for normal progression of dopaminergic neurotransmission. This is supported by the often observed deregulation of abovementioned processes in several pathological nervous system disorders. Consequently, future research focusing on the effects of these processes on DA release from dopaminergic neurons might provide important insights in dopaminergic neurotransmission and brain disorders.

\section{THE MOLECULAR MACHINERY OF QUANTAL DA RELEASE AND VESICLE CYCLING}

The frequency of quantal DA release is a major determinant of neurotransmission. Vesicles have to be docked and primed by the molecular exocytotic machinery before an elevation in $\left[\mathrm{Ca}^{2+}\right]_{\mathrm{i}}$ can trigger vesicle fusion. Consequently, the release frequency can be modulated by the number of vesicles available for release as well as by the molecular interactions underlying docking, priming and vesicle fusion, as will be shown below for catecholaminereleasing neuroendocrine cells.

\section{The Actin Network and Vesicle Fusion}

The number of vesicles available for docking and priming is regulated by synapsins, a class of vesicleassociated proteins that can link vesicles to a filamentous, submembranal actin network [89-91], i.e., in a so-called reserve pool of vesicles. Phosphorylation of synapsin, by PKA, PKC and $\mathrm{Ca}^{2+}$-calmodulin-dependent protein kinase II (CaMKII), decreases its interaction with actin, resulting in an increased availability of vesicles for docking. Decreasing phosphorylation of synapsins, by protein phosphatase $2 \mathrm{~A}$ and $\mathrm{Ca}^{2+}$-calmodulin-dependent protein phosphatase $2 \mathrm{~B}$ (calcineurin), reduces the availability of vesicles for docking $[89,90]$. The importance of synapsins for vesicle availability was demonstrated using mutant mice lacking synapsin I, which shows a marked decrease in the number of releasable vesicles and in the maximum release rate [92,93]. Moreover, using specific anti-synapsin antibodies, it was demonstrated in Aplysia neurons that synapsins do not directly affect the readily releasable pool of vesicles but instead are required for vesicle recruitment from the reserve pool [90].

The cortical actin network acts as a barrier for vesicle docking, requiring disassembly of this network for vesicle translocation [91]. Disassembly of the actin network in chromaffin cells is achieved by cell depolarization, PKC activity and activation of nicotinic receptors. Disassembly precedes exocytosis, whereas re-assembly of the actin network occurs upon termination of stimulation, and is regulated in a $\mathrm{Ca}^{2+}$-dependent manner by scinderin [91]. Actin disassembly and $\mathrm{Ca}^{2+}$-induced catecholamine release are enhanced by addition of recombinant scinderin to permeabilized chromaffin cells; this effect was reversed by phosphatidylinositol 4,5-biphosphate [94] and treatment with scinderin antisense [95]. Phorbol ester-induced PKC activation results in disassembly of the actin network as well, which is prevented by PKC inhibitors [91, 96]. This suggests that PKC activation, which is known for many years to increase the releasable pool of vesicles and catecholamine secretion, regulates the size of the releasable vesicle pool at least partly through disassembly of the actin network. This is underlined by an amperometric study demonstrating an increase in the number of readily releasable vesicles following PKC-mediated actin disassembly in chromaffin cells [96]. Fusion of DA-containing SV fusion in dopaminergic neurons is enhanced following phorbol esterinduced PKC activation as well [97], though it is presently unclear whether this is related to PKC-mediated actin disassembly. The PKC-mediated disassembly of the actin network is probably mediated by phosphorylation of a Myristoylated Alanine-Rich C Kinase Substrate (MARCKS). Apparently, unphosphorylated MARCKS stabilizes the actin network, whereas phosphorylation results in network disassembly and vesicle translocation from the reserve pool to the readily releasable pool of vesicles [91]. The phosphorylation of MARCKS is enhanced by mitochondrial inhibitors, which potentiate the secretory response and increase actin disassembly. Both phosphorylation of MARCKS and actin disassembly, induced by mitochondrial inhibitors, are inhibited by PKC inhibition, suggesting that normally, rapid sequestration of $\mathrm{Ca}^{2+}$ by mitochondria limits PKC activation and subsequent phosphorylation of MARCKS and actin disassembly, thereby limiting the extent of the secretory response [98]. Both the scinderin and the MARCKS pathway act in parallel to disassemble the actin network; which pathway is predominant appears to depend on the kind of stimulation [91].

A minimal actin network appears critical for the final vesicle fusion event, as application of high concentrations of actin-disrupting agents, e.g. cytochalasin D, inhibit 
exocytosis [99]. Using a combination of amperometry and confocal microscopy in permeabilized chromaffin cells it was shown that drugs that inhibit the activity of myosin specifically affect the slow phase of secretion occurring $>5 \mathrm{~s}$ after $\mathrm{Ca}^{2+}$-application, as well as the secretory response to subsequent stimulations, and strongly reduce vesicle mobility [100]. The actin-stabilizing agent phalloidin specifically decreases the initial burst of exocytosis, i.e. $<5 \mathrm{~s}$ after depolarization, as well [100]. Moreover, overexpression of unphosphorylatable form of myosin regulatory light chain, which prevent myosin motor proteins from interacting with the actin network, reduces vesicle mobility, the initial and slow phase of evoked-exocytosis and slows the fusion kinetics of individual granules [101], indicating that myosin is not only implicated in the transport of vesicles but in the final phases of exocytosis as well. Taken together, the actin network not only acts as a negative clamp for exocytosis, but, together with myosin, is an essential component for vesicle movement and the final fusion event as well. Consequently, deregulation of actin and/or myosin function likely affects both the number of releasable vesicles and the kinetics of single exocytotic events, at least in neuroendocrine chromaffin cells. Future studies, using dopaminergic neurons, can reveal whether these mechanisms apply to neuronal DA exocytosis as well.

\section{The Molecular Release Machinery}

The basic molecular machinery underlying membrane fusion is well-studied and the current knowledge has been summarized in a large number of reviews [1,102-105]. Therefore, in this section an overview is provided on some aspects of the molecular machinery, followed by examples demonstrating the importance of these aspects for quantal catecholamine/DA release from neuroendocrine cells.

Upon reaching the cell membrane, secretory vesicles are docked through formation of the SNARE-complex consisting of vesicle-associated synaptobrevin (v-SNARE) and plasma membrane-associated synaptosomal associated protein of $25 \mathrm{kDa}$ (SNAP-25) and syntaxin (t-SNAREs) [1,102-105]. Obviously, prevention of SNARE-complex formation, or disruption of this complex, prevents vesicles from docking and subsequent priming and release. Classic examples of impairment of vesicle exocytosis are provided by exposure to botulinum neurotoxin (BoNT) or tetanus neurotoxin (TeNT). Depending on the type of neurotoxin, one of the SNARE proteins is cleaved, resulting in failure of synaptic transmission, paralysis and, in severe cases, death [106]. Using amperometry it was shown in neuroendocrine chromaffin cells that BoNT/A and BoNT/E, which cleave SNAP-25, strongly reduce exocytosis [107-109]. Similar results were observed following exposure to BoNT/C1, which cleaves syntaxin and SNAP-25, as well as to BoNT/D and TeNT light chains, which cleave synaptobrevin, demonstrating the requirement for SNARE-complex formation in exocytosis [108-109]. Nowadays, certain isoforms of these neurotoxins are used to treat several neurological disorders, including migraine, tremors and dystonia [110]. As these neurotoxins affect exocytosis in general, the potential of these toxins as therapeutic agents for treatment of hyperactivity of the dopaminergic system will depend on the ability to target these toxins specifically to the neurons that innervate the dopaminergic system or to the dopaminergic system itself.

The t-SNARE syntaxin is normally bound to Munc18, preventing formation of the SNARE-complex. Phosphorylation of Munc18 by PKC or cyclin-dependent kinase $5(\mathrm{Cdk} 5)$ decreases its affinity for syntaxin, thus allowing the interaction of syntaxin with SNAP-25 and synaptobrevin [1,102-105,111]. Chromaffin cells lacking Munc18-1 display a strong reduction in LDCV exocytosis and in the number of morphologically docked LDCVs, whereas overexpression of Munc18-1 increases the amount of releasable vesicles and accelerates repletion of the releasable pool of vesicles [112]. Expression of a Munc18 mutant with reduced affinity for syntaxin, modifies the kinetics of single exocytotic events, consistent with an acceleration of fusion pore expansion [113], whereas expression of syntaxin with reduced binding to Munc18 results in an increased vesicle contents size and a slowing of the kinetics of release [114]. The effects of Munc18 on fusion pore expansion, the kinetics of single exocytotic events and vesicle contents size appear controlled by phosphorylation of Munc18 by both PKC and Cdk5 $[115,116]$. Thus Munc18 functions in an early (docking) stage of the fusion process, as well as in a late stage of the fusion process by binding to syntaxin, thereby limiting the availability of syntaxin for SNARE-complex formation. The dissociation of Munc18 from syntaxin apparently determines the kinetics of the final fusion events.

Munc13 is one of the proteins that is now believed to play a central role in the priming reaction, which has to occur before fusion competence is gained [1,104,105]. Munc13 is able to interact with syntaxin and has a phorbol ester binding site, activation of which potentiates exocytosis [117]. The putative essential role of Munc13 in exocytosis is based on the absence of exocytosis in Munc13-deficient mice, though the number of docked vesicles is not reduced [118]. Munc13 overexpressing chromaffin cells display an increase in both the fast and slow component of LDCV exocytosis as measured using amperometry. However, the response to a second stimulation is greatly reduced, indicating a depletion of release-competent vesicles. As the number of docked vesicles is unchanged, these results suggest that Munc13 is involved in LDCV priming by accelerating the rate constant of vesicle transfer from a pool of docked, but unprimed vesicles to a pool of releasecompetent, primed vesicles [119].

Following priming, $\mathrm{Ca}^{2+}$-dependent triggering of LDCV fusion requires a specific cytosolic factor, $\mathrm{Ca}^{2+}$-dependent Activator Protein for Secretion (CAPS), which localizes selectively to plasma membranes and to LDCVs, but not to SVs [120]. Introduction of CAPS antibodies in chromaffin cells reduces the initial exocytotic burst, representing the readily releasable vesicle pool. Additionally, amperometric spikes are much smaller and broader, suggesting that CAPS plays a role in determining release of vesicle contents via the fusion pore [121]. Moreover, $\mathrm{Ca}^{2+}$ is ineffective in triggering vesicle fusion following ATP-dependent priming in the absence of CAPS, indicating CAPS functions to enhance $\mathrm{Ca}^{2+}$-dependent LDCV exocytosis by acting at an unidentified rate-limiting, $\mathrm{Ca}^{2+}$-dependent prefusion step [122]. These combined results are consistent with a 
widespread functional role of CAPS in the regulated exocytosis of LDCVs in the nervous and endocrine systems, though the abundance of CAPS in synaptic terminals indicates that CAPS may also be important for neuronal functions not exclusively related to LDCV exocytosis.

The proposed $\mathrm{Ca}^{2+}$-sensor synaptotagmin (Syt), which exists in several isoforms, prevents the SNARE-complex from further interactions until an increase in the $\left[\mathrm{Ca}^{2+}\right]_{i}$ displaces Syt and catalyses membrane fusion. Syt contains two $\mathrm{Ca}^{2+}$-binding $\mathrm{C} 2$ domains and exhibits $\mathrm{Ca}^{2+}$-dependent phospholipid, syntaxin and SNAP-25 binding properties. Syt has been proposed to facilitate endocytosis and to modulate $\mathrm{Ca}^{2+}$-channels, fusion pore kinetics and the mode of exocytosis $[1,102-105,123,124]$. One of the isoforms, Syt-I, was previously demonstrated to be essential for fast, synchronous $\mathrm{Ca}^{2+}$-dependent exocytosis in various cell types $[123,125,126]$. Amperometric studies revealed that Syt-Ideficient chromaffin cells display prolonged exocytotic delays and slow, $\mathrm{Ca}^{2+}$-dependent fusion rates, resulting in strongly reduced LDCV release in response to short depolarizations, demonstrating that Syt-I is required for rapid, highly $\mathrm{Ca}^{2+}$-sensitive LDCV exocytosis [126]. Chromaffin cells carrying a mutated Syt C2A domain, which increases the $\mathrm{K}_{\mathrm{D}}$ of $\mathrm{Ca}^{2+}$-dependent phospholipid binding to the double C2A-C2B domain of Syt, display slower secretory rates, longer secretory delays, and a higher intracellular $\mathrm{Ca}^{2+}$-threshold for secretion. Thus, $\mathrm{Ca}^{2+}$ dependent phospholipid binding to Syt-I mirrors the intracellular $\mathrm{Ca}^{2+}$ dependence of exocytosis [127]. These results indicate that Syt-I is essential for triggering fast synchronous neurotransmitter release and suppression of slow asynchronous release, which is likely mediated by other Syt isoforms or other $\mathrm{Ca}^{2+}$-sensing proteins. Amperometric studies also demonstrate the involvement of Syt in the regulation of fusion pore kinetics and the mode of exocytosis (see Endocytosis and kiss-and-run section).

In addition to Syt, other proteins might be involved in late or final steps of $\mathrm{Ca}^{2+}$-dependent exocytosis. One of these is a neural cytosolic protein that acts as a positive regulator of exocytosis, known as complexin (CPX). CPX, of which two closely related isoforms exist, binds only to the assembled SNARE-complex and competes with alpha-SNAP for binding to the SNARE-complex, suggesting that complexins may modulate neurotransmitter release process $[1,104,105,128]$. The potential importance of CPX is further underlined by the fact that CPX II KO mice display deficits of motor, behavioral and cognitive function [129]. These deficits are strikingly similar to those seen in the R6/2 mouse model of Huntington's disease (HD), where a progressive depletion of CPX II is seen [130]. Moreover, CPX II levels are markedly reduced in post-mortem striatum of patients with HD [131]. A similar loss of CPX is seen in PC12 cells expressing the HD mutation. Using amperometry it was shown that this loss in CPX II is accompanied by a dramatic decline in $\mathrm{Ca}^{2+}$-triggered catecholamine exocytosis, which can be rescued by expression of CPX II [132]. Moreover, overexpression of CPX II in chromaffin cells modified the kinetics of single exocytotic events so that their time course was shortened, consistent with a function of complexin in stabilizing an intermediate of the SNARE-complex to allow kiss-and-run exocytosis [133]. These combined data suggest that depletion of CPX II modulates single vesicle exocytosis and could thereby contribute to the cognitive abnormalities in R6/2 mice and HD.

After fusion, the actions of N-ethylmaleimide-sensitive fusion protein (NSF) and alpha-soluble NSF attachment protein (alpha-SNAP) are required to disassemble the SNARE-complex for future rounds of vesicle fusion. Additionally, alpha-SNAP and NSF have been reported to have a role in priming as well [102-104]. The important role of these proteins was demonstrated in a series of amperometric experiments in chromaffin cells. Chromaffin cells dialyzed with a solution containing alpha-SNAP display enhanced exocytosis upon repeated depolarizations. This increase is not observed following dialysis with mutant alpha-SNAP which was unable to bind syntaxin [134]. Moreover, alpha-SNAP increases the amplitude of the exocytotic burst and the slow component following flashphotolysis of caged $\mathrm{Ca}^{2+}$, but does not change their kinetics [135]. The stimulatory action of alpha-SNAP on exocytosis requires ATP hydrolysis mediated via NSF. This action of alpha-SNAP is significant only at $\left[\mathrm{Ca}^{2+}\right]_{i}$ between 100 and $300 \mathrm{nM}$, suggesting that alpha-SNAP enhances a component of exocytosis that is regulated by a high-affinity $\mathrm{Ca}^{2+}$ sensor [136]. On the other hand, expression of a dominant negative alpha-SNAP(L294A) substantially inhibits LDCV exocytosis, without affecting the amplitude and characteristics of the single exocytotic events [137]. These results indicate that alpha-SNAP has a stimulatory effect on exocytosis and suggest an important role for alphaSNAP/NSF in priming granules for release at an early step, but not in the final fusion process.

Summarizing, the basic release machinery is provided by the SNARE-complex, whereas the temporal regulation appears at least partly mediated by the proposed $\mathrm{Ca}^{2+}$-sensor Syt. The additional involvement of a large number of regulatory proteins, including but certainly not limited to alpha-SNAP, NSF, Munc18, Munc13, CAPS and CPX, enables the regulation required for proper neurotransmission under a range of different conditions. As described above, interference with one of the normally occurring interactions can result in profound effects on neurotransmission.

\section{Modulation of the Molecular Release Machinery by Phosphorylation}

Protein kinase mediated phosphorylation affects numerous mechanisms involved in neurotransmission, including the regulation of ligand-gated ion channels [138], the dynamics and disassembly of the actin network [91], DAT activity [139] and the late steps of exocytosis, i.e. the final fusion event [140]. Consequently, protein phosphatases play a key role in neurotransmission as well, since they can counteract the protein kinase-induced phosphorylation and change the basal levels of phosphorylation, which can result in profound effects [141].

PKA is widely expressed and has profound effects on many aspects related to dopaminergic neurotransmission $[102,142]$. Activation of the cAMP/PKA pathway is known to prevent the $\mathrm{Ca}^{2+}$-induced inhibition of L-type $\mathrm{Ca}^{2+}$ channels [143] and could thereby prolong the exocytotic response upon intense and prolonged stimulation. In rat striatum, depolarization-evoked DA release is markedly reduced by PKA inhibitors [144]. As constitutive PKA 
activity appears necessary to maintain a large number of vesicles in the readily releasable pool of vesicles, the SNARE protein SNAP-25 is a likely PKA target mediating the stimulatory effects on exocytosis [145]. Overexpression of SNAP-25a, mutated in a PKA phosphorylation site (Thr138), eliminates the effect of PKA inhibitors on the vesicle priming process. Another, unidentified, PKA target appears responsible for regulation of the relative size of two different primed vesicle pools, which are distinguished by their release kinetics [145]. Additionally, PKA appears to affect the late steps of vesicle fusion. Forskolin, which increases the intracellular cAMP levels, increases the amount of catecholamines released per vesicle in neuroendocrine chromaffin cells, which is accompanied by a slowing down of the release kinetics. These effects are not due to newly synthesized catecholamines and suggest that cAMP/PKA might favor granule aggregation before fusion with the cell membrane and slow the late step of the exocytotic process $[140,146]$. This is further supported by the finding that tonic activity of PKA near the cell membrane appears to modulate the amount of catecholamines released per vesicle, as well as the size of the readily releasable pool of vesicles, and could thereby regulate neurotransmitter release [147]. These combined data indicate that PKA, in addition to its effects on $\mathrm{Ca}^{2+}$ entry, regulates neurotransmitter release by modulating the size of the primed pool of vesicles as well as the amount of neurotransmitter released per vesicle in neuroendocrine cells. Whether this applies to dopaminergic neurons as well, largely remains to be established.

PKC is probably the best studied protein kinase with respects to neurotransmission. Phorbol esters are potent activators of $\mathrm{PKC}$ and enhance basal and evoked catecholamine and DA release from neuronal and neuroendocrine preparations [144,148-151]. The effects of phorbol ester on neurotransmitter release are suppressed by inhibition of PKC, absent under $\mathrm{Ca}^{2+}$-free conditions and prevented by chronic phorbol ester treatment, i.e. downregulation of PKC [148-150]. Treatment of permeabilized chromaffin cells with phorbol esters selectively potentiates the ATP-dependent priming step, which is at least partly mediated by PKC-induced phosphorylation of GAP-43 [148]. Phorbol ester-induced PKC activation has also been reported to increase basal catecholamine exocytosis via a selective shift in the activation of L-type $\mathrm{Ca}^{2+}$ channels, resulting in an increase in $\left[\mathrm{Ca}^{2+}\right]_{\mathrm{i}}$ under resting conditions [149]. However, activation of PKC has also been reported to decrease depolarizationinduced catecholamine release in intact PC12 and chromaffin cells [151,152]. This is caused by a reduction in the frequency of exocytotic events [151] and likely due to alterations in $\mathrm{Ca}^{2+}$ entry as phorbol ester-induced PKC activation strongly inhibited $\left[\mathrm{Ca}^{2+}\right]_{\mathrm{i}}$ transients evoked by $\mathrm{K}^{+}$ and the L-type $\mathrm{Ca}^{2+}$ channel activator Bay $\mathrm{K} 8644$ [152]. PKC is also implicated in vesicle trafficking and redistribution. In resting neuroendocrine PC12 cells, LDCVs are distributed throughout the cytoplasm, whereas vesicles redistribute towards the plasma membrane following phorbol ester-induced PKC activation [153]. In neurons, a comparable redistribution from the cell body to neurites was observed following PKC activation. This redistribution is, at least partly, mediated by PKC-MARCKS signaling pathways [154; see also The actin network and vesicle fusion section].
Additionally, activation of PKC appears to modify the kinetics of single exocytotic events in chromaffin cells [140]. Following phorbol ester treatment, the mean half-width of amperometric events decreases, whereas the rate of the initial rise and the fall to baseline of the spikes increase, resulting in a decreased total charge. This suggest that PKC regulates the rate of fusion pore expansion and subsequent pore closure, thereby modulating the amount of catecholamines released per fusion event [109]. Finally, AMPH increases $\mathrm{PKC}$ activity in striatum, which could be responsible for AMPH-induced increases in striatal DA release. The increased PKC activity is linked to AMPH-induced outward transport of dopamine through the DAT. When transportermediated release is diminished, the inward transport of AMPH inhibits PKC activity instead [155]. As PKC inhibitors significantly attenuate the MDMA-induced increase in the extracellular concentration of DA in the striatum, whereas PKC activation significantly increases MDMA-induced DA release [156], PKC may prove to be an important target for treatment of adverse effects of certain classes of drugs of abuse and psychostimulants. The combined results demonstrate that PKC modulates a variety of presynaptic processes involved in neurotransmission, including vesicle trafficking, priming and release. The actual effect of PKC modulation will depend on the cellular composition and might thus vary in different cell types.

Inhibition of $\mathrm{Ca}^{2+} /$ calmodulin-dependent protein kinase II (CaMKII) was reported to reduce evoked catecholamine secretion from neuroendocrine PC12 and chromaffin cells $[157,158]$, as well as basal and evoked DA release from rat striatum [144]. Moreover, CaMKII, as PKC, could play a key role in the AMPH-induced DAT-mediated DA efflux, which is enhanced in schizophrenic patients. Correspondingly, CaMKII mRNA levels are elevated in post-mortem schizophrenia frontal cortex [159]. AMPHinduced DA efflux in striatum was $\mathrm{Ca}^{2+}$-dependent and accompanied by increased CaMKII activity and increased phosphorylation of synapsin I at a site specifically phosphorylated by CaMKII [160]. Though the AMPH effect appears primarily mediated by DAT, the CaMKII-induced increased phosphorylation of synapsin I suggests that vesicular DA release may be affected as well [see amphetamine section for more details]. The combined results indicate that CaMKII likely is an important modulator of vesicular catecholamine and DA release.

Calmodulin has a modulatory role in exocytosis [161]. As $\mathrm{Ca}^{2+} /$ calmodulin can bind to a C-terminal domain of synaptobrevin, and this calmodulin- and phospholipidbinding domain of synaptobrevin is required for $\mathrm{Ca}^{2+}$ dependent exocytosis [162], calmodulin may modulate exocytosis by regulating SNARE-complex assembly. Moreover, calmodulin can bind to CaMKII and $\mathrm{Ca}^{2+}$ channels, underlining the importance of calmodulin as a modulator of exocytosis. Application of calmodulin in permeabilized chromaffin cells increases $\mathrm{Ca}^{2+}$-dependent catecholamine release in a dose-dependent manner, whereas calmodulin antagonists inhibit $\mathrm{Ca}^{2+}$-dependent exocytosis [151,161-163]. The observed enhancement of the basal release frequency in intact $\mathrm{PC} 12$ cells by inhibition of calmodulin, could be mediated by an effect on basal $\mathrm{Ca}^{2+}$ homeostasis [151]. Inhibition of calmodulin was shown to decrease the amount of catecholamines released per vesicle 
[163]. As comparable results could not be reproduced in another study using a 3-fold lower concentration of calmodulin inhibitors [151], the involvement of calmodulin in fusion pore formation and/or vesicle filling remains a matter of debate.

Phosphatases dephosphorylate proteins previously phosphorylated by protein kinases. As several protein kinases strongly affect vesicular DA release, phosphatases could have profound effects on DA exocytosis as well $[141,164]$. Though the actions of phosphatases are less well characterized, present evidence supports the notion that exocytosis is tuned by the balance between phosphorylation and dephosphorylation, with increased phosphorylation enhancing exocytosis. In line with this, inhibition of protein phosphatase types $1,2 \mathrm{~A}$ and $2 \mathrm{~B}$ (calcineurin), increases basal catecholamine secretion in intact and permeabilized chromaffin and PC12 cells, by increasing the frequency of exocytosis [151,165]. Nonetheless, further studies are required to determine the exact molecular targets of these phosphatases in basal and stimulation-induced DA exocytosis, from both neuroendocrine cells and dopaminergic neurons.

\section{$\mathrm{Ca}^{2+}$ SIGNALING AND VESICLE FUSION}

As already mentioned, exocytosis is triggered by an increase in the $\left[\mathrm{Ca}^{2+}\right]_{\mathrm{i}}[1,102-105,123]$. Additionally, $\mathrm{Ca}^{2+}$ ions regulate the activity of a variety of cytoplasmic proteins involved in the regulation of the vesicle cycle and are implicated in presynaptic plasticity [166-168]. As a result of the major role of $\mathrm{Ca}^{2+}$, neurons and neuroendocrine cells have to continuously maintain a low baseline $\left[\mathrm{Ca}^{2+}\right]_{i}$ and have to exert a sharp control over the dynamics of their $\mathrm{Ca}^{2+}$ signals. To do so, requires a strong control over the balance between $\mathrm{Ca}^{2+}$ influx and extrusion, $\mathrm{Ca}^{2+}$ sequestration and $\mathrm{Ca}^{2+}$ buffering by cytosolic $\mathrm{Ca}^{2+}$ binding proteins (CaBPs).

\section{Voltage-Sensitive $\mathrm{Ca}^{2+}$ Channels}

One important pathway to increase the $\left[\mathrm{Ca}^{2+}\right]_{\mathrm{i}}$ is $\mathrm{Ca}^{2+}$ influx through voltage-sensitive $\mathrm{Ca}^{2+}$ channels (VSCC) located in the plasma membrane. VSCCs are divided in several pharmacologically and functionally distinct types, including L-, N-, T-, R- and P/Q-type $\mathrm{Ca}^{2+}$ channels, which are all strongly implicated in the regulation of DA/catecholamine secretion from both neurons and neuroendocrine cells [169-174]. The types of $\mathrm{Ca}^{2+}$ channels involved in $\mathrm{Ca}^{2+}$ entry and subsequent neurotransmitter release differ between various cell types and even with the type of stimulus [175-185, Table $\mathbf{2 A}$ ). In line with these findings, L-type $\mathrm{Ca}^{2+}$ channel agonists have been reported to dose-dependently potentiate locomotor activity [186], whereas $\mathrm{N}$ - and P/Q-type $\mathrm{Ca}^{2+}$ channel antagonists dosedependently inhibit some forms of drug-induced hyperactivity [187]. Consequently, $\mathrm{Ca}^{2+}$ channel antagonists have widely been used in the treatment of neurological and cardiovascular disorders, albeit sometimes with parkinsonism and movement disorders as side effects [188], and antagonism of $\mathrm{Ca}^{2+}$ channels may ameliorate activation of the dopaminergic system induced by DA hyperactivity. Moreover, depolarization-evoked DA release is significantly inhibited by purified immunoglobulin $\mathrm{G}$ from Amyotrophic Lateral Sclerosis patients, supporting a role for L-type $\mathrm{Ca}^{2+}$ channels in the pathogenesis of this disease [189].

As VSCC are crucial for regulating $\mathrm{Ca}^{2+}$ entry and subsequent exocytosis, they are subject to modulation by various factors, including autoinhibition and autocrine modulation [143,178,190-200, Table 2 B]. Additionally, numerous exogenous factors modulate $\mathrm{Ca}^{2+}$ entry through VSCC. Opioids, ethanol, volatile anaesthetics, intravenous anaesthetic agents and barbiturates, as well as heavy metals (see Heavy metals section), all inhibit $\mathrm{Ca}^{2+}$ channel-mediated $\mathrm{Ca}^{2+}$ entry as well as catecholamine secretion in both

Table 2

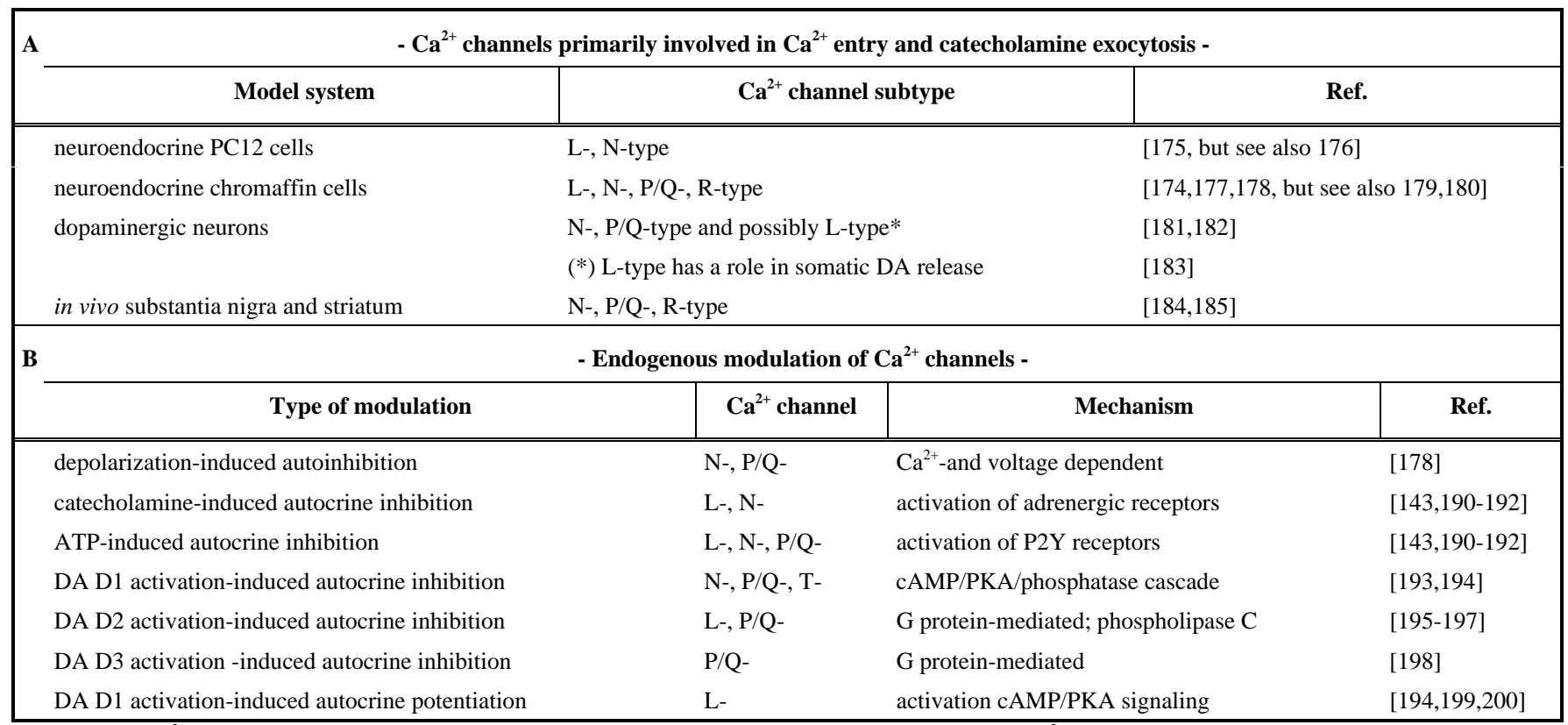

Involvement of $\mathrm{Ca}^{2+}$ channels in the modulation of exocytosis. A) Depending on the cell type (first column) different Ca ${ }^{2+}$ channel subtypes (second column) are primarily involved in $\mathrm{Ca}^{2+}$ entry and subsequent catecholamine exocytosis. B) $\mathrm{Ca}^{2+}$ channels are modulated by a variety of autocrine feedback mechanisms (first column), which effect only a subset of $\mathrm{Ca}^{2+}$ channel subtypes (second column) through the mechanisms indicated (third column). 
neuroendocrine cells and striatal slices [143,190-192,201204]. Moreover, both glucocorticoids as well as neurotrophic factors are able to modulate $\mathrm{Ca}^{2+}$ entry through VSCC and subsequent exocytosis [205; see growth factors and hormones section]. Differentiation of neuroendocrine PC12 cells with glucocorticoids increased the expression of VSCC, thereby enhancing the frequency of depolarization-induced exocytosis [206]. Additionally, GDNF rapidly and reversibly potentiates VSCC currents as well as exocytosis in cultured dopaminergic neurons [207].

$\mathrm{Ca}^{2+}$ channels not only allow for $\mathrm{Ca}^{2+}$ entry required for triggering exocytosis, but also interact directly with SNARE proteins. Synaptotagmins and synaptotagmin-SNAREcomplexes associate with $\mathrm{N}$ - and P/Q-type $\mathrm{Ca}^{2+}$ channels, which may serve to co-localize the $\mathrm{Ca}^{2+}$ sensor that triggers exocytosis within a microdomain of $\mathrm{Ca}^{2+}$ entry $[170,172,208,209]$. The interaction of $\mathrm{N}$-type $\mathrm{Ca}^{2+}$ channels with SNARE-complexes is modulated by $\mathrm{Ca}^{2+}, \mathrm{PKC}$ and CaMKII. Changes in this interaction are paralleled by changes in neurotransmitter release and the amount of docked vesicles. This suggests that presynaptic $\mathrm{Ca}^{2+}$ channels not only provide the $\mathrm{Ca}^{2+}$ signal required for exocytosis, but also contain structural elements that play a role in vesicle docking, priming, and fusion processes and enable a rapid secretory response to an incoming signal [170,172,208,209]. More recently, syntaxin has been shown to interacts with and modify the channel kinetics of the cardiac L-type and neuronal R-type $\mathrm{Ca}^{2+}$ channels [210], further strengthening the importance of $\mathrm{Ca}^{2+}$ channels in the modulation of neurotransmitter release.

$\mathrm{Ca}^{2+}$ entry via VSCCs has also been reported to play a role in hypoxia-induced catecholamine release. Hypoxia induces depolarization via inhibition of a TEA-sensitive $\mathrm{K}^{+}$ conductance, resulting in $\mathrm{Ca}^{2+}$ influx through $\mathrm{L}-$ and $\mathrm{N}$-type $\mathrm{Ca}^{2+}$ channels and potentiation of catecholamine secretion. Additionally, hypoxia-induced catecholamine secretion is related to an up-regulation of L-type $\mathrm{Ca}^{2+}$ channels, formation of a $\mathrm{Cd}^{2+}$-resistant $\mathrm{Ca}^{2+}$ influx pathway and an increase in the amount of catecholamines released per vesicle. Hypoxia-induced catecholamine exocytosis is severely reduced by inhibitors of Alzheimer's diseaseassociated amyloid beta-peptides (AbetaPs), including an $\mathrm{N}$ terminus-directed monoclonal antibody, whereas the hypoxia-induced effects are mimicked by exposure of normoxic cells to AbetaPs [211-213]. Antioxidants fully blocked the enhancement of catecholamine exocytosis and augmentation of whole-cell $\mathrm{Ca}^{2+}$ currents caused by both chronic hypoxia and by application of AbetaP. AbetaP formation and resulting elevated levels of reactive oxygen species, appeared to be an absolute requirement for the effects of hypoxia on $\left[\mathrm{Ca}^{2+}\right]_{\mathrm{i}}$ and catecholamine release $[212,213]$. Recently, opioid agonists were shown to inhibit the hypoxia-induced increase in $\left[\mathrm{Ca}^{2+}\right]_{\mathrm{i}}$ and $\mathrm{Ca}^{2+}$ influx through antagonism of hypoxia-induced changes in $\mathrm{K}^{+}$ conductance [214], suggesting that future research may turn up with useful opioid agonists as potential drugs for the treatment of Alzheimer disease.

\section{Intracellular Stores and $\mathrm{Ca}^{2+}$-Exchangers}

The $\left[\mathrm{Ca}^{2+}\right]_{\mathrm{i}}$ can be increased by $\mathrm{Ca}^{2+}$ release from intracellular stores, including endoplasmic reticulum (ER) and mitochondria (for $\mathrm{Ca}^{2+}$ storage in secretory vesicles see intravesicular storage section). Intracellular stores can be divided in IP3- and ryanodine-sensitive stores. The release of $\mathrm{Ca}^{2+}$ from these stores plays an important role in secretion and can be achieved by a variety of stimulants, including $\mathrm{Ca}^{2+}$-induced $\mathrm{Ca}^{2+}$ release (CICR) [173,215]. On the other hand, these stores can take up excess cytosolic $\mathrm{Ca}^{2+}$ after stimulation to terminate the $\mathrm{Ca}^{2+}$ signal and restore the $\left[\mathrm{Ca}^{2+}\right]_{\mathrm{i}}$ to baseline levels. Thus, intracellular $\mathrm{Ca}^{2+}$ stores can modulate secretion either behaving as a $\mathrm{Ca}^{2+}$ sink to terminate secretion or as a $\mathrm{Ca}^{2+}$ source to induce or potentiate secretion.

Generation of IP3, e.g. by histamine-induced activation of phospholipase $\mathrm{C}$, leads to $\mathrm{Ca}^{2+}$ mobilization from internal stores in neuroendocrine cells. Mobilization of IP3-sensitive intracellular $\mathrm{Ca}^{2+}$ stores induces an increase in the $\left[\mathrm{Ca}^{2+}\right]_{\mathrm{i}}$ and subsequent exocytosis [215,216]. Moreover, transient elevation of the $\left[\mathrm{Ca}^{2+}\right]_{i}$ with a brief histamine treatment enhances subsequent secretory responses. However, the enhancement of secretion is absent in cells pretreated with thapsigargin, which prevents $\mathrm{Ca}^{2+}$ storage in the ER by inhibiting the ER $\mathrm{Ca}^{2+}$ ATPase pump. Therefore, these results suggest that intracellular $\mathrm{Ca}^{2+}$ stores are vital for the continuation of exocytosis during repetitive stimulation [217]. Furthermore, IP3 elicits a sharp and transient rise in $\left[\mathrm{Ca}^{2+}\right]_{\mathrm{i}}$ in dopaminergic neurons, which could be prevented by depletion of intracellular IP3-sensitive $\mathrm{Ca}^{2+}$ stores [218]. Stimulation of neuroendocrine chromaffin cells by caffeine results in a transient increase in $\left[\mathrm{Ca}^{2+}\right]_{\mathrm{i}}$ and subsequent exocytosis, which is prevented by prior depletion of intracellular $\mathrm{Ca}^{2+}$ stores [216,219,220]. Moreover, caffeine produces an outward $\mathrm{K}^{+}$current mediated by $\mathrm{Ca}^{2+}$ released from internal $\mathrm{Ca}^{2+}$ stores in chromaffin cells [219]. In striatal slices, caffeine-induced intracellular $\mathrm{Ca}^{2+}$ mobilization and subsequent DA release likely underlie the hypermotor activity observed after caffeine application [221]. Furthermore, caffeine enhances the frequency and the amplitude of spontaneous hyperpolarizations in dopaminergic neurons [222].

Depletion of intracellular $\mathrm{Ca}^{2+}$ stores in neuroendocrine cells not only elevates the $\left[\mathrm{Ca}^{2+}\right]_{i}$, but induces a sustained phase of $\mathrm{Ca}^{2+}$ entry through a non-voltage dependent pathway as well $[175,223]$. The $\mathrm{Ca}^{2+}$ current that is activated by store depletion is called $\mathrm{Ca}^{2+}$ release-activated $\mathrm{Ca}^{2+}$ current (ICRAC) [224]. This process of $\mathrm{Ca}^{2+}$ influx is known as capacitive or store-operated $\mathrm{Ca}^{2+}$ entry and, of course, requires the presence of extracellular $\mathrm{Ca}^{2+}[225,226] . \mathrm{Ca}^{2+}$ entry through this pathway is sufficient to stimulate exocytosis at negative membrane potentials. In addition, depolarization-evoked exocytosis is markedly facilitated on activation of this current [175,223], indicating that storeoperated $\mathrm{Ca}^{2+}$ influx may modulate excitation-secretion coupling.

Activation of $\mathrm{Ca}^{2+}$ channels on the plasma membrane and on intracellular $\mathrm{Ca}^{2+}$ stores generates local transient increases in the cytosolic $\left[\mathrm{Ca}^{2+}\right]$. This results in rapid $\mathrm{Ca}^{2+}$ uptake by neighboring mitochondria to terminate the transient increase in cytosolic $\left[\mathrm{Ca}^{2+}\right]$. Fast mitochondrial $\mathrm{Ca}^{2+}$ uptake has a rather low $\mathrm{Ca}^{2+}$ affinity. Only stimulation that induces a high local $\left[\mathrm{Ca}^{2+}\right]$ can fully activate mitochondrial $\mathrm{Ca}^{2+}$ uptake [227,228]. Abolishing mitochondrial $\mathrm{Ca}^{2+}$ uptake results in a 
reduced decay of the $\left[\mathrm{Ca}^{2+}\right]_{\mathrm{i}}$ and in a strong increase in catecholamine exocytosis in neuroendocrine cells [227-229], indicating that mitochondria modulate secretion by controlling the availability of $\mathrm{Ca}^{2+}$ for exocytosis.

The $\mathrm{Na}^{+} / \mathrm{Ca}^{2+}$ exchanger (NCX) normally removes excessive $\mathrm{Ca}^{2+}$ from the cytosol after stimulation and, together with mitochondrial $\mathrm{Ca}^{2+}$ uptake and the ER $\mathrm{Ca}^{2+}$ pump, restores the $\left[\mathrm{Ca}^{2+}\right]_{\mathrm{i}}$ to baseline levels. Reversal of the NCX by changing the normal inward gradient of $\mathrm{Na}^{+}$, results in a strong increase in $\left[\mathrm{Ca}^{2+}\right]_{\mathrm{i}}$ and enhancement of catecholamine release [230-232]. Additionally, inhibition of plasma membrane $\mathrm{Ca}^{2+}$-ATPases and NCX substantially increases catecholamine secretion induced by agents that mobilize intracellular $\mathrm{Ca}^{2+}$ stores, e.g. histamine, caffeine and thapsigargin. Moreover, the rise in cytosolic $\left[\mathrm{Ca}^{2+}\right]$ during mobilization of intracellular $\mathrm{Ca}^{2+}$ stores is enhanced and prolonged following inhibition of plasma membrane $\mathrm{Ca}^{2+}$-ATPases and NCX, suggesting that the efficacy of intracellular $\mathrm{Ca}^{2+}$ stores in evoking exocytosis is enhanced dramatically by inhibiting $\mathrm{Ca}^{2+}$ efflux from the cell [233]. However, under normal conditions the NCX appears to function only in the initial phase of $\left[\mathrm{Ca}^{2+}\right]$ i decay and when the ER $\mathrm{Ca}^{2+}$ pump is blocked [229]. Thus, intracellular $\mathrm{Ca}^{2+}$ stores and $\mathrm{Ca}^{2+}$ exchangers play an important role in modulating exocytosis and even in regulating the excitability of midbrain dopaminergic neurons and neuroendocrine cells.

\section{$\mathrm{Ca}^{2+}$ Binding Proteins}

Neurons and neuroendocrine cells contain an array of CaBPs, that are likely to play an important role in $\mathrm{Ca}^{2+}$ buffering and thus may affect the $\left[\mathrm{Ca}^{2+}\right]$ at vesicle release sites [171,234]. One of these proteins is Calbindin- $\mathrm{D}_{28 \mathrm{~K}}$ (CB), which is abundantly present in several brain areas and neuroendocrine cells [238, Westerink et al., submitted] and is involved in the regulation of the $\left[\mathrm{Ca}^{2+}\right]_{\mathrm{i}}$ in a variety of cell types [235-237]. Recently, it was shown that the number of vesicles released upon repeated depolarizations is strongly reduced in CB-deficient chromaffin cells. This coincides with a reduction in the amount of catecholamines released per vesicle, which is suggestive for incomplete release, i.e. kiss-and-run exocytosis [Westerink et al., submitted]. These effects of $\mathrm{CB}$ are probably the result of changes in $\mathrm{Ca}^{2+}$-entry and in short-term submembranal $\mathrm{Ca}^{2+}$-homeostasis. Interestingly, $\mathrm{CB}$ has been reported to be neuroprotective [236] and the expression of $\mathrm{CB}$ in ventral mesencephalon dopaminergic neurons is enhanced by brain-derived neurotrophic factor (BDNF) [238]. Moreover, the progression of some neurological diseases, including Amyotrophic Lateral Sclerosis, is paralleled by low levels of CB [239], underlining the importance of proper $\mathrm{Ca}^{2+}$ buffering by CaBPs.

Neuronal $\mathrm{Ca}^{2+}$ Sensor 1 (NCS-1), which is expressed in neurons and neuroendocrine cells, has been implicated in the modulation of neurotransmitter release and in the regulation of VSCCs [240,241]. NCS-1 was shown to down-regulate VSCCs [242], whereas NCS-1 overexpression enhances neurotransmitter release in chromaffin cells [243]. As exogenous NCS-1 is without effects on $\mathrm{Ca}^{2+}$-dependent catecholamine release in permeabilized chromaffin cells, it was suggested that the effects of NCS-1 seen in intact cells are likely due to an action on the early steps of stimulus- secretion coupling or on $\mathrm{Ca}^{2+}$ homeostasis [244]. The interaction of NCS-1 with phosphatidylinositol 4hydroxykinase appears to underlie the stimulatory effects of NCS-1 on exocytosis by modulating vesicle trafficking in a phosphoinositide-dependent manner [243,245]. Moreover, increases in NCS-1 change paired-pulse depression into paired-pulse facilitation without altering basal synaptic transmission or initial neurotransmitter release probability in cultured hippocampal neurons [246]. These results indicate that NCS-1 strongly modulates exocytosis, though direct changes of NCS-1 on dopaminergic neurotransmission are scarce. Therefore, it is noteworthy that NCS-1 can mediate desensitization of DA D2 receptors. NCS-1 is found in close proximity to intracellular $\mathrm{Ca}^{2+}$ stores and in association with both the D2 receptor and G-protein-coupled receptor kinase 2 , a regulator of D2 receptor desensitization. NCS-1 attenuates agonist-induced receptor internalization via a mechanism that involves both a reduction in D2 receptor phosphorylation as well as an increase in D2 receptormediated cAMP inhibition after DA stimulation. It is therefore suggested that NCS-1 plays a key role in dopaminergic neurotransmission, possibly because the NCS1/D2 receptor interaction couples DA and $\mathrm{Ca}^{2+}$ signaling pathways [247].

\section{ENDOCYTOSIS AND KISS-AND-RUN}

Endocytosis, the recycling of secretory vesicles following exocytosis, is a critical feature of neuronal communication as it ensures a constant supply of vesicles for neurotransmitter release and prevents excessive swelling of the presynaptic cell. Endocytosis, which critically depends on $\mathrm{Ca}^{2+}$, allows for the selective and efficient retrieval of the specialized membrane structures of secretory vesicles. Following refilling with neurotransmitter, the recycled vesicles can participate in successive rounds of exocytosis. The process of exocytosis and subsequent endocytosis follows one of two pathways, i.e., full-fusion and subsequent clathrin-mediated endocytosis or kiss-and-run exocytosis [102,248-251]. The mode of exocytosis and subsequent endocytosis is of critical importance as it may not only modulate the release frequency, but the time course of the release event and the amount of transmitter released per event as well.

During full-fusion, as originally proposed by Heuser and Reese [252], neurotransmitter-containing vesicles completely fuse with the cell membrane. The vesicular membrane components are subsequently recovered by clathrin-mediated endocytosis, i.e. pinched off as a 'coated vesicle'. These coated vesicles fuse with a sorting endosome from which new secretory vesicles emerge. The alternative for full-fusion was proposed by Ceccarelli and coworkers [253] and is now widely known as kiss-and-run exocytosis. During kiss-and-run exocytosis, fusion is transient and secretion occurs solely via a fusion pore [254]. After closing of the fusion pore, the vesicles are retrieved rapidly and completely without loss of identity, instead of undergoing clathrin-mediated endocytosis [102,248-251]. Kiss-and-run exocytosis could be a mechanism to keep up with highfrequency stimulation. Moreover, kiss-and-run exocytosis could be a means to regulate quantal size, with the open time of the fusion pore determining the amount of neurotransmitter released per vesicle. Finally, during kiss- 
and-run exocytosis, LDCV retain their dense-core, which is made up of granins [255], thereby preventing graninmediated feedback. Consequently, factors that regulate the dynamics of the fusion pore or control the choice between full fusion and kiss-and-run exocytosis are critical for neurotransmission and are likely to play a role in synaptic plasticity [256].

The first direct proof for the existence of kiss-and-run exocytosis was obtained in mast and chromaffin cells using an elegant combination of cell-attached capacitance measurements with carbon-fiber microelectrode amperometry [6,7]. It was occasionally found that the narrow fusion pore forms only transiently without expanding, i.e. without full fusion of the vesicle with the plasma membrane. This allows for complete emptying of the vesicle as demonstrated by the presence of a normal amperometric spike $[6,7]$. A strong increase in extracellular $\left[\mathrm{Ca}^{2+}\right]$ shifts the preferred mode of exocytosis to the kiss-and-run mechanism in a $\mathrm{Ca}^{2+}$ concentration-dependent manner in chromaffin cells. This suggests that the mode of exocytosis is modulated at least partly by $\mathrm{Ca}^{2+}$ to attain optimal conditions for coupled exocytosis and endocytosis according to synaptic activity [257]. In line with this, it has been suggested that neurotrophins, like BDNF, may elicit a switch from the slow to the fast mode of endocytosis by modulating $\mathrm{Ca}^{2+}$ microdomains associated with VSCC at active zones [205]. Kiss-and-run exocytosis is not restricted to neuroendocrine chromaffin cells, but is widely occurring in other neuroendocrine and neuronal systems as well $[11,258$ 261].

In cortical nerve terminals, glutamate release occurs via two mechanisms, i.e. PKC-independent full fusion and PKCdependent kiss-and-run exocytosis [259]. This is in line with some amperometric studies using chromaffin cells where PKC activation was reported to increase the kinetics of single exocytotic events and to decrease the amount of neurotransmitter released per vesicle, suggesting that PKC regulates the rate of fusion pore expansion and subsequent pore closure [109,262]. Moreover, CPX II and Cdk5 have been reported to regulate fusion pore dynamics in neuroendocrine cells, suggesting a role for these proteins in kiss-and-run exocytosis as well [116,133]. Amperometric recordings of DA release from SVs of ventral midbrain neurons indicate that SV fusion pores flicker either once or several times in rapid succession, with each flicker releasing approximately $25-30 \%$ of vesicular dopamine. The incidence of events with multiple flickers is reciprocally regulated by PKC activation and inhibition [97]. Thus, dopaminergic neurons regulate the amount of neurotransmitter released from SVs by controlling the number of fusion pore flickers per exocytotic event. This mode of exocytosis, which likely is a variant of kiss-and-run exocytosis, is a potential mechanism whereby dopaminergic neurons can rapidly reuse vesicles without undergoing the comparatively slow process of recycling.

One of the proteins that appears critically involved in determining the mode of exocytosis is Syt. Using amperometry, synaptotagmins were shown to modulate fusion pore dynamics. Overexpression of Syt-I in neuroendocrine PC12 cells prolongs the time from fusion pore opening to pore dilation, whereas Syt-IV shortens this time. Transfection with Syt-IV, or increasing endogenous Syt-IV by forskolin treatment, increases the frequency and duration of kiss-and-run events. Full fusion is inhibited by mutation of a $\mathrm{Ca}^{2+}$ ligand in the $\mathrm{C} 2 \mathrm{~A}$ domain of Syt-I, whereas kiss-and-run exocytosis is inhibited by mutation of a homologous $\mathrm{Ca}^{2+}$ ligand in the $\mathrm{C} 2 \mathrm{~B}$ domain of Syt-IV. This demonstrates that synaptotagmins regulate the balance between full fusion and kiss-and-run, with $\mathrm{Ca}^{2+}$ binding to the C2A and C2B domains and their interaction with SNAP$25 /$ syntaxin, playing an important role in this balance $[263,264]$. The GTPase dynamin I binds to the vesicle protein synaptophysin in a $\mathrm{Ca}^{2+}$-dependent way suggesting that a dynamin/synaptophysin complex functions in vesicle recycling. In $\mathrm{PC} 12$ cells, the immediate recapture of secretory granules after fusion pore formation is inhibited after inhibition of dynamin [265]. In chromaffin cells, a rapid form of endocytosis, likely to be kiss-and-run exocytosis, also depends on dynamin I, whereas a much slower form depends on dynamin II [266]. Moreover, mean vesicle contents and the half-width and fall time of amperometric spikes are increased following disruption of dynamin function, suggesting that a dynamin-dependent process can prevent vesicles from undergoing full fusion [262].

Thus, kiss-and-run exocytosis is a widely occurring $\mathrm{Ca}^{2+}$. and PKC-dependent pathway for vesicle cycling. Kiss-andrun is mediated by synaptotagmins and dynamin I and possibly CPX II and Cdk5. Increasing the incidence of kissand-run exocytosis may affect the demand for vesicle supply and could consequently affect the release frequency. More importantly, kiss-and-run exocytosis could limit the amount of neurotransmitter released per fusion event or change the time course of single fusion events. This would greatly affect the [DA] at nearby target receptors and might even change brain DA levels. Likely, future studies will provide details on kiss-and-run exocytosis, its modulation and its consequences for brain DA levels and target receptors. Depending on the outcome of these studies, kiss-and-run exocytosis might well be an upcoming target for understanding neurological disorders and developing therapeutic strategies.

\section{ENDOGENOUS AND EXOGENOUS FACTORS MODULATING CATECHOLAMINE/DA EXOCY- TOSIS}

\section{Growth Factors and Hormones}

Growth factors and hormones can induce differentiation and alter cellular homeostasis in dopaminergic neurons and neuroendocrine cells. Of these factors, nerve growth factor (NGF) is often used to differentiate PC12 cells towards a more neuronal cell system with increased voltage-dependent $\mathrm{Na}^{+}$and $\mathrm{Ca}^{2+}$ currents, and neurite extension [267,268]. An amperometric study demonstrated that upon NGFdifferentiation, $\mathrm{PC} 12$ cells release catecholamines primarily from varicosities along their neurites with no release from the cell body. The number of exocytotic events observed decreases as the cells become more neuronal in character, though the mean vesicle contents is not significantly altered upon differentiation [269]. Upon acute application of NGF, $\mathrm{Ca}^{2+}$-induced DA release from intact and permeabilized PC12 cells is enhanced, possibly as a result of an increased 
number of secretory vesicles in the readily releasable pool mediated by activation of tyrosine kinase-linked receptor TrkA [270].

Glucocorticoids, like corticosterone and cortisol, are secreted upon elevated stress levels and affect a variety of neuronal and neuroendocrine pathways. Corticosterone, an important stress hormone, regulates dopaminergic neurotransmission at the level of DA D-1 receptors and DA synthesis [271,272]. Chronic exposure to the synthetic glucocorticoid dexamethasone, which induces a chromaffin cell-like phenotype in neuroendocrine PC12 cells, was shown to increase the activity of $\mathrm{TH}$, the amount of stored catecholamines, the $\mathrm{Ca}^{2+}$ current magnitude, the frequency of depolarization-induced catecholamine exocytosis, and the amount of catecholamines released per fusion event [206,273,274]. In line with this, corticosterone increases extracellular [DA] and locomotor activity, whereas suppression of endogenous glucocorticoid secretion decreases basal and depolarization-induced DA release in the NAcc as well as apomorphine-induced locomotor activity [275]. These effects are mediated by the membraneassociated glucocorticoid receptor, since blockade of these receptors dose-dependently reduces locomotor activity as well as the basal and depolarization-induced DA release in the NAcc [276]. The combined results suggest that glucocorticoids and glucocorticoid receptor antagonists may prove to be very valuable for treatment of DA induced behavioral disturbances and disorders.

Estrogens have been shown to modulate DA receptor expression and function and the synthesis, release, uptake and metabolism of DA in neurons and neuroendocrine cells [277]. The nigrostriatal DA system is sexually dimorphic, as striatal DA activity is modulated by gonadal steroid hormones in female but not male rats [278-280], which may partly explain the gender differences in response to drugs of abuse. The exact mechanism through which estrogen exerts its effect on the dopaminergic system remains a matter of debate, though it likely includes the beta isoform of the estrogen receptor, which is found only in subsets of neurons [281]. The effects of estrogens on dopaminergic neurotransmission appear to be mediated by $\mathrm{Ca}^{2+}$-signaling pathways, as 17-beta-estradiol directly increased $\left[\mathrm{Ca}^{2+}\right]_{i}$ in a dose-dependent manner in primary cultures from embryonic mouse midbrains. The increase in $\left[\mathrm{Ca}^{2+}\right]_{i}$ was due to $\mathrm{Ca}^{2+}$ release from intracellular $\mathrm{Ca}^{2+}$ stores. However, it was not restricted to dopaminergic neurons, but occurred in GABAergic neurons as well [282]. Conversely, high concentrations of estrogens inhibited $\mathrm{Ca}^{2+}$ entry in neuroendocrine chromaffin cells [283]. Additionally, estradiol rapidly uncouples $\mu$-opioid and GABAB receptors from G-protein-gated inwardly rectifying $\mathrm{K}^{+}$channels in dopaminergic neurons, which could affect excitability of dopaminergic neurons and subsequently DA release [284]. In neuroendocrine chromaffin cells, estrogens modify the kinetics of single exocytotic events. Application of nanomolar concentrations of estrogens produced a profound slowing down of exocytosis, as measured by amperometry, without alterations in the total amount of catecholamines released per exocytotic event. These low concentrations of estradiol increased the intracellular cAMP levels, suggesting the involvement of PKA in the observed slowing down of exocytosis [283]. Whether this holds for DA release from dopaminergic neurons as well remains to be established. Notably, DA release in striatum and NAcc evoked by the neurotoxin $\mathrm{MPP}^{+}$is dose-dependently reduced in the presence of estrogen [280]. Moreover, estrogen inhibits the clearance of DA in both the striatum and NAcc. This indicates that estrogen may function as a neuroprotectant by reducing the uptake of both DA and of the neurotoxin into dopaminergic neurons [280]. Thus, estrogens have profound effects on DA release from dopaminergic neurons and neuroendocrine cells, mediated by both genomic (long term) and nongenomic (short term) mechanisms. Moreover, the effects on dopaminergic systems suggest a neuroprotective role for estrogens and may implicate that hormonal modulation of nigrostriatal dopaminergic neurotoxicity may represent an important variable responsible for the sex differences which are reported in PD.

The neurotrophin BDNF promotes the survival and differentiation of cultured nigral dopaminergic neurons. BDNF is synthesized in the pyramidal layer of cerebral cortex and released in the striatum [285]. BDNF is responsible for inducing normal expression of the DA D3 receptor in NAcc during development and in adulthood and can trigger overexpression of the D3 receptor in striatum of hemiparkinsonian rats [286; Sokoloff et al, this issue]. Moreover, BDNF increases neostriatal levels of DA and increases depolarization-induced DA release from ventral mesencephalon dopaminergic neurons [238]. Additionally, BDNF potentiates the depolarization-induced release of GABA, DA and serotonin in striatal slices. This potentiation is dependent on activation of the high-affinity tyrosine kinase-linked receptor TrkB as well as on membrane depolarization, as BDNF alone is incapable of potentiating release [287]. Though the precise mechanisms of action are currently unknown, these results indicate that BDNF potentiates depolarization-induced vesicular DA release [205]. Consequently, BDNF may have a potential role in the treatment of PD as it potentiates DA release and is able to affect D3 receptor expression.

GDNF is known to affect DA release as well as the survival and differentiation of dopaminergic neurons of the midbrain. Though GDNF rapidly and reversibly potentiates voltage-activated $\mathrm{Ca}^{2+}$ currents as well as the amplitude and frequency of spontaneous and evoked excitatory autaptic currents in dopaminergic neurons [207], GDNF is particularly noted for its delayed (days-weeks), long-term (days-weeks) effects, which occur even after a single administration. A single GDNF administration increases $\mathrm{K}^{+}$evoked DA overflow throughout the striatum and in primary cultures of dopaminergic neurons, without affecting the release of GABA or the basal levels of DA $[38,238,288]$. The enhancement of DA overflow is likely caused by increased DA synthesis as GDNF strongly increases TH phosphorylation [288]. In support of this view, amperometric recordings demonstrated a $>3$ fold increase in the amount of DA released per exocytotic event in dopaminergic neurons [38]. Chronic application of GDNF leads to comparable effects, i.e. increased excitatory autaptic currents and increased frequency of spontaneous miniature excitatory autaptic currents in dopaminergic neurons. Moreover, chronically applied GDNF increases the number of dopaminergic terminals in cultured dopaminergic neurons, without affecting release of GABA or the number of 
terminals from GABAergic neurons [289]. As the effects of GDNF are mainly restricted to dopaminergic neurons, serious attempts were made to investigate the possibility to treat PD with GDNF. Administration of GDNF in animal models of PD increases $\mathrm{TH}$ expression in striatum, ameliorates behavioral symptoms, allows protection of nigral dopaminergic neurons against lesion-induced cell death and improves survival and differentiation of embryonic dopaminergic neuronal grafts [290,291]. Summarizing, GDNF acts, at least partly, by increasing TH-mediated DA synthesis, which is reflected in an increased amount of DA released per vesicle and an increased number of DA releasing terminals. Consequently, GDNF increases brain DA levels, making it a valuable tool for future treatments of dopaminergic disorders.

\section{PCBs}

Polychlorinated biphenyls $(P C B s)$, which persist in the environment and accumulate in biological tissues, induce behavioral symptoms, alterations in brain neurotransmitter levels and alterations in the amount of basal and evoked neurotransmitter release from cell populations [292]. Numerous studies have been performed to elucidate the mechanisms underlying the effects of PCBs on neurotransmission. PCBs were reported to alter the $\left[\mathrm{Ca}^{2+}\right]_{\mathrm{i}}$, striatal DA levels, intracellular DA content and DA synthesis through inhibition of TH, VMAT and DAT in neurons and neuroendocrine cells [292-296]. As these effects provide a strong indication that PCBs can alter vesicular neurotransmitter, it is surprising that to date in only one study the effects of PCBs on quantal neurotransmitter release were investigated. Acute exposure of neuroendocrine PC12 cells to the nonplanar congener PCB 4 and to the coplanar congener PCB 126, but not exposure to the nonplanar congener PCB 128, increases the basal frequency of catecholamine exocytosis. Though, acute and subchronic exposure failed to cause changes in the contents of catecholamine-containing vesicles in this study [297]. Consequently, additional experiments are required to elucidate the effects of PCBs on quantal catecholamine/DA release in both neuroendocrine cells and dopaminergic neurons.

\section{Heavy Metals}

Heavy metals, including $\mathrm{Cd}^{2+}, \mathrm{Pb}^{2+}$ and $\mathrm{Mn}^{2+}$, are known to exert numerous adverse effects, including disturbance of the metabolism of brain neurotransmitters, neurotransmission and behavior [298]. A variety of metal effects on voltage- and ligand-gated ion channels, depending on metal species and concentration, have been reported [299]. A large number of heavy metals exert effects on VSCCs. The inhibition of $\mathrm{Ca}^{2+}$ entry by $\mathrm{Cd}^{2+}$-induced block of VSCCs and subsequent inhibition of evoked neurotransmitter release is well known. However, $\mathrm{Cd}^{2+}$ has also been reported to increase basal catecholamine secretion from chromaffin cells by increasing cytosolic free $\left[\mathrm{Ca}^{2+}\right]$ [300] as well as by a direct effect on the exocytotic machinery [301]. More recently, using a combination of amperometry and membrane capacitance measurements, the vesicular origin of $\mathrm{Cd}^{2+}$-evoked catecholamine secretion, and of secretion induced by several other metals, including $\mathrm{Sr}^{2+}$, could be demonstrated in PC12 cells [302].

Exposure to the heavy metal $\mathrm{Pb}^{2+}$, as with $\mathrm{Cd}^{2+}$, was reported to exert biphasic effects. Depolarization-evoked DA overflow in NAcc is increased after chronic exposure to low concentrations of $\mathrm{Pb}^{2+}$, whereas DA clearance time is reduced [303]. On the other hand, acute exposure to $\mathrm{Pb}^{2+}$ inhibits evoked neurotransmitter release, at least partly by inhibition of VSCCs, whereas spontaneous neurotransmitter release is enhanced following a short delay [301,304-306]. Recently, amperometry was used to demonstrate that $\mathrm{Pb}^{2+}$ induced exocytosis in neuroendocrine PC12 cells is mediated through direct effects on intracellular mechanisms, without apparent changes in the intracellular $\left[\mathrm{Ca}^{2+}\right]$ and in vesicle contents. In addition, a low-affinity intracellular effect of $\mathrm{Pb}^{2+}$, leading to inhibition of exocytosis in permeabilized cells, was observed [274]. $\mathrm{Pb}^{2+}$-evoked exocytosis in permeabilized PC12 cells appears insensitive to modulation of PKC and calcineurin activity, though it is strongly reduced by inhibition of CaMKII, indicating that CaMKII plays a role in $\mathrm{Pb}^{2+}$-induced catecholamine release from PC12 cells [151]. Additionally, nanomolar concentrations of $\mathrm{Pb}^{2+}$ catalyze the interaction of the C2A domain of Syt-I with phospholipid liposomes and protect Syt-I from proteolytic cleavage in a manner similar to $\mathrm{Ca}^{2+}$. However, $\mathrm{Pb}^{2+}$ is unable to promote the interaction of Syt-I with syntaxin and is a competitive inhibitor of the Syt-I-syntaxin interaction induced by micromolar concentrations of $\mathrm{Ca}^{2+}$ [307].

$\mathrm{Sr}^{2+}$ was reported to induce catecholamine exocytosis from intact and permeabilized chromaffin cells, through an indirect effect that is secondary to the displacement of bound $\mathrm{Ca}^{2+}[301,308]$. More recently it was shown that $\mathrm{Sr}^{2+}$. induced exocytosis has a vesicular origin and could be mediated by $\mathrm{Sr}^{2+}$ - binding to the proposed $\mathrm{Ca}^{2+}$-sensor [302]. In support of this, the fast component of both $\mathrm{Ca}^{2+}-$ and $\mathrm{Sr}^{2+}-$ induced exocytosis is selectively impaired in Syt-I KO mice. $\mathrm{Sr}^{2+}$-induced exocytosis is mediated by binding of $\mathrm{Sr}^{2+}$ to the C2B domain of Syt-I. As with $\mathrm{Pb}^{2+}, \mathrm{Sr}^{2+}$ is unable to promote the interaction of Syt-I with SNARE proteins [309]. These findings indicate that the proposed $\mathrm{Ca}^{2+}$ sensor Syt likely plays an important role in the potentiating effects of heavy metals on exocytosis.

Chronic exposure to manganese $(\mathrm{Mn})$ causes selective toxicity to the nigrostriatal dopaminergic system, resulting in a Parkinsonian-like neurological condition which is known as Manganism. Manganism is likely the result of extensive apoptosis and irreversible DA depletion. $\mathrm{Mn}^{2+}$-induced apoptosis appears mediated by proteolytic activation of protein kinase Cdelta via a mitochondrial-dependent caspase- 3 cascade [310]. $\mathrm{Mn}^{2+}$ enters the cytoplasm through membrane associated channels, in particular VSCCs, and the NCX to exert its adverse effects [311,312]. In addition to inducing apoptosis, entry of $\mathrm{Mn}^{2+}$ induces catecholamine release in neuroendocrine chromaffin cells and striatal synaptosomes [311,312], indicating that $\mathrm{Mn}^{2+}$ is a surrogate for $\mathrm{Ca}^{2+}$ in triggering and maintaining catecholamine release. Interestingly, $\mathrm{Mn}^{2+}$ also stimulates phosphorylation of MARCKS (see the actin network and vesicle fusion section), which could contribute to the catecholamine-releasing action of $\mathrm{Mn}^{2+}$, though $\mathrm{Mn}^{2+}$, unlike $\mathrm{Ca}^{2+}$, does not stimulate an increase in $\mathrm{TH}$ phosphorylation [311]. On the other hand, 
$\mathrm{Mn}^{2+}$ was reported to inhibit $\mathrm{Ca}^{2+}$-evoked catecholamine release from permeabilized chromaffin cells [301]. It is obvious that $\mathrm{Mn}$ can severely affect dopaminergic neurotransmission due to its apoptotic effects as well as its capability to affect catecholamine release. However, the exact underlying mechanisms are not fully unraveled yet, though the net effect of Mn exposure likely depends on dose and exposure time, as well as on the valency state of $\mathrm{Mn}$ [313].

Thus, heavy metals exert multiple differential effects on VSCCs, intracellular $\mathrm{Ca}^{2+}$ stores and multiple cellular targets, which depending on exposure time and concentration, result in either inhibition or potentiation of vesicular catecholamine release. Consequently, exposure to heavy metals provides a potential risk for proper dopaminergic neurotransmission.

\section{Solvents}

The organic solvent toluene, which is occasionally used as a drug of abuse, causes a variety of neurotoxic and neuropathological effects [314]. It was recently shown that, in addition to several postsynaptic effects [314-316], toluene induces vesicular catecholamine release in PC12 cells. Toluene enhances basal exocytosis but is without effects on depolarization-induced catecholamine exocytosis, indicating that the exocytotic process remains intact. Toluene-induced exocytosis depends on the influx of extracellular $\mathrm{Ca}^{2+}$ through VSCCs [317]. However, in another study it was shown that toluene does not increase the $\left[\mathrm{Ca}^{2+}\right]_{i}$, but dosedependently inhibits the depolarization-induced rise in $\left[\mathrm{Ca}^{2+}\right]_{\mathrm{i}}[318]$. These rather contradictory results might be explained by the differences in the differentiation of the used PC12 cells, i.e., dexamethasone-differentiated cells vs. NGFdifferentiated cells, which affects $\mathrm{Ca}^{2+}$ channel expression and density. Nonetheless, the increase in catecholamine exocytosis as observed in the amperometric study is in agreement with the reported elevated levels of extracellular DA in rat brain [315] and suggest that toluene affects dopaminergic neurotransmission which may result in the solvent-induced neuropathies.

\section{Amphetamine}

With respect to dopaminergic neurotransmission, AMPH is probably the best studied drug of abuse. AMPH is long known to increase extracellular DA levels in brain [25]. As a substrate of DAT, AMPH affects the excitability of DA neurons, reduces DA uptake and enhances DA release through reverse transport, thereby increasing basal extracellular DA levels in brain and limiting the availability of DA for vesicle filling [DA uptake section]. The DA releasing action of AMPH is potentiated by the ability of AMPH to both redistribute vesicular DA to the cytosol and to increase $\left[\mathrm{Ca}^{2+}\right]_{\mathrm{i}}$ sufficiently for triggering exocytosis [Vesicular monoamine transporter section]. Moreover, the ability of AMPH, as well as of METH, to increase DA synthesis in dopaminergic neurons further contributes to the elevation of cytosolic DA levels [25,319]. The accumulation of cytosolic DA and subsequent oxidation to quinones and reactive oxygen species may contribute significantly to the observed neurodegeneration following METH exposure $[319,320]$. Due to the effects of AMPH on DA uptake and vesicle filling, it is expected that AMPH exposure reduces the amount of DA released per vesicle. Proof that this is indeed the case was obtained from amperometric recordings using PC12 cells [22] and DA-containing neurons of Planorbis corneus [321]. In addition to decreasing vesicle contents, AMPH reduces the frequency of nicotine-induced exocytotic events from chromaffin cells, as demonstrated using amperometry $[65,70]$. On the other hand, basal exocytosis is enhanced because of the AMPH-triggered $\mathrm{Ca}^{2+}$ release from vesicular stores [65,70].

Thus, AMPH-induced DA release appears primarily mediated by DAT, though it is also mediated by vesicle fusion due to the release of vesicular $\mathrm{Ca}^{2+}$. As the amount of DA released per vesicle is decreased and background levels of DA are increased, AMPH strongly influences the signal to noise ratio of evoked DA signals, which could have important consequences. Additionally, AMPH is able to increase the activity of PKC and CaMKII, which likely enhances the adverse effects of this drug of abuse [Modulation of the molecular release machinery by phosphorylation section]. AMPH is often the drug of choice in the treatment of attention-deficit hyperactivity disorder (ADHD). ADHD is likely caused by dysfunction of dopaminergic and noradrenergic systems and is characterized by a variety of symptoms, including hyperactivity, impulsivity, poorly sustained attention and developmental behavioral deficiencies. The behavioral disturbances observed in animal models of ADHD appear to be the result of an imbalance between noradrenergic and dopaminergic systems in the prefrontal cortex, with inhibitory dopaminergic activity being decreased and noradrenergic activity increased relative to controls. Application of AMPH preferentially increased DA levels, resulting in amelioration of the symptoms $[322,323]$. As the exact nature of dopaminergic dysfunction in ADHD is unknown, future research will have to reveal whether the dysfunction resides at the level of DA storage, synthesis or release (either through reverse transport or by exocytosis) and may consequently aid in developing new therapeutic strategies for treatment.

\section{CONCLUSION AND PERSPECTIVES}

Dopaminergic neurotransmission is involved in motor movement, reward and cognitive behavior, and responses to drugs of abuse. Deregulation can result in severe disorders, including ADHD, PD and schizophrenia. Under normal conditions, DA is released mainly from axons, as well as from dendrites and from the soma of dopaminergic neurons. DA can be released through exocytosis to exert its effects on both nearby and remote target receptors, though DATmediated reverse transport plays an important role as well. DA receptor activation affects DA synthesis, VMAT functioning, a PKC-mediated component of AMPH-induced DA efflux, PKA-mediated long-term potentiation and $\mathrm{Ca}^{2+}$ channel modulation. DA can inhibit its own release through DA autoreceptors. In mice lacking D2 autoreceptors, or in mice in which D2 receptors are antagonized using haloperidol, autoinhibition of DA release is impaired $[324,325]$ and extracellular DA levels in brain are increased. Moreover, DA autoreceptor activation upregulates DATmediated DA clearance [325] as well as the excitability of 
dopaminergic neurons. Consequently, DA autoreceptors may prove to be a specific and important target for therapeutic strategies.

DA exocytosis is tightly regulated. Formation, filling, translocation and fusion of DA-containing vesicles, as well as the underlying mechanisms, are all initiated and coordinated by sophisticated interactions between a large number of molecular players. Many of these have been identified in the last decade and our understanding of these interactions aided considerably in the how and why of dopaminergic neurotransmission and disorders related to the dopaminergic system. Nonetheless, the list of key players in the process of vesicle exocytosis is still growing rapidly. Even though exocytosis is tightly regulated by multiple, sophisticated interactions, it can be easily deregulated, as should be clear from the above. Though science is far from a total understanding of DA exocytosis and its consequences for dopaminergic neurotransmission in the healthy and diseased brain, these and future studies, directed to pin-point additional ways to deregulate exocytosis, will certainly contribute to the emerging picture. As changes in DA release are likely to affect the extracellular levels of DA, these in vitro findings in neuroendocrine cells are certainly relevant. However, presently, one can only speculate on the functional in vivo consequences of these changes. Consequently, in vivo observations of changes in extracellular DA levels can be related to basic cellular mechanisms with great difficulty only.

\section{ABBREVIATIONS}

\begin{tabular}{|c|c|c|}
\hline$\left[\mathrm{Ca}^{2+}\right]_{\mathrm{i}}$ & $=$ & Intracellular $\mathrm{Ca}^{2+}$ concentration \\
\hline AbetaP & $=$ & Amyloid beta-peptide \\
\hline ADHD & $=$ & Attention-deficit hyperactivity disorder \\
\hline alpha-SNAP & $=$ & Soluble NSF attachment protein \\
\hline alpha-Syn & $=$ & Alpha-synuclein \\
\hline AMPH & $=$ & Amphetamine \\
\hline BDNF & $=$ & Brain-derived neurotrophic factor \\
\hline BoNT & $=$ & Botulinum neurotoxin \\
\hline $\mathrm{CaBP}$ & $=$ & $\mathrm{Ca}^{2+}$ binding protein \\
\hline calcineurin & $=$ & $\begin{array}{l}\mathrm{Ca}^{2+} \text {-calmodulin-dependent protein phos- } \\
\text { phatase } 2 \mathrm{~B}\end{array}$ \\
\hline CaMKII & $=$ & $\begin{array}{l}\mathrm{Ca}^{2+} \text {-calmodulin-dependent protein kinase } \\
\text { II }\end{array}$ \\
\hline CAPS & $=$ & $\begin{array}{l}\mathrm{Ca}^{2+} \text {-dependent activator protein for } \\
\text { secretion }\end{array}$ \\
\hline $\mathrm{CB}$ & $=$ & Calbindin- $\mathrm{D}_{28 \mathrm{~K}}$ \\
\hline Cdk5 & $=$ & Cyclin-dependent kinase 5 \\
\hline $\mathrm{CgA}$ & $=$ & Chromogranin A \\
\hline $\mathrm{CgB}$ & $=$ & Chromogranin B \\
\hline CPX & $=$ & Complexin \\
\hline DA & $=$ & Dopamine \\
\hline DAT & $=$ & Membrane dopamine transporter \\
\hline & $=$ & Endoplasmic reticulum \\
\hline
\end{tabular}

\begin{tabular}{|c|c|c|}
\hline ERK & $=$ & Extracellular signal-regulated kinase \\
\hline GDNF & $=$ & Glial cell line-derived neurotrophic factor \\
\hline HD & $=$ & Huntington's Disease \\
\hline IP3 & $=$ & Inositol-1,4,5-triphosphate \\
\hline LDCV & $=$ & Large dense-core vesicle \\
\hline L-DOPA & $=$ & L-3,4-dihydroxyphenylalanine \\
\hline MAO & $=$ & Monoamine oxidase \\
\hline MARCKS & $=$ & $\begin{array}{l}\text { Myristoylated Alanine-Rich C Kinase } \\
\text { Substrate }\end{array}$ \\
\hline MDMA & $=$ & 3,4-methylenedioxymethamphetamine \\
\hline METH & $=$ & Methamphetamine \\
\hline MPTP & $=$ & $\begin{array}{l}\text { 1-methyl-4-phenyl-1,2,3,6-tetrahydro- } \\
\text { pyridine }\end{array}$ \\
\hline NAcc & $=$ & Nucleus Accumbens \\
\hline NCS-1 & $=$ & Neuronal $\mathrm{Ca}^{2+}$ sensor 1 \\
\hline NCX & $=$ & $\mathrm{Na}^{+} / \mathrm{Ca}^{2+}$ exchanger \\
\hline NGF & $=$ & Nerve growth factor \\
\hline NSF & $=$ & N-ethylmaleimide-sensitive fusion protein \\
\hline PD & $=$ & Parkinson's Disease \\
\hline PCB & $=$ & Polychlorinated biphenyl \\
\hline PKA & $=$ & cAMP-dependent protein kinase A \\
\hline $\mathrm{PKC}$ & $=$ & Protein kinase $\mathrm{C}$ \\
\hline SDCV & $=$ & Small dense-core vesicle \\
\hline SN & $=$ & Substantia nigra \\
\hline SNAP-25 & $=$ & $\begin{array}{l}\text { Synaptosomal-associated protein of } 25 \\
\mathrm{kDa}\end{array}$ \\
\hline SNARE & $=$ & Soluble NSF Attachment protein Receptor \\
\hline SV & $=$ & Synaptic vesicle \\
\hline Syt & $=$ & Synaptotagmin \\
\hline TeNT & $=$ & Tetanus neurotoxin \\
\hline $\mathrm{TH}$ & $=$ & Tyrosine hydroxylase \\
\hline VMAT & $=$ & Vesicular MonoAmine Transporter \\
\hline VSCC & $=$ & Voltage-sensitive $\mathrm{Ca}^{2+}$ channel \\
\hline
\end{tabular}

\section{REFERENCES}

[1] Südhof, T.C. Annu. Rev. Neurosci., 2004, 27, 509.

[2] Agnati, L.F.; Fuxe, K.; Nicholson, C.; Syková, E. Volume Transmission Revisited, Elsevier: Amsterdam, 2000.

[3] Westerink, R.H.S. Neurotoxicology, 2004, 25, 461.

[4] Fatt, P.; Katz, B. J. Physiol. (Lond), 1952, 117, 109.

[5] Gillis, K.D. In Single channel recording; Sakmann, Neher, Eds.; Plenum Press, New York, 1995; 155-198.

[6] Albillos, A.; Dernick, G.; Horstmann, H.; Almers, W.; Alvarez de Toledo, G.; Lindau, M. Nature, 1997, 389, 509.

[7] Alvarez de Toledo, G.; Fernandez-Chacon, R.; Fernandez, J.M. Nature, 1993, 363, 554.

[8] Klyachko, V.A.; Jackson, M.B. Nature, 2002, 418, 89

[9] Ryan, T.A. Curr. Opin. Neurobiol., 2001, 11, 544.

[10] Toomre, D.; Manstein, D.J. Trends Cell Biol., 2001, 11, 298.

[11] Williams, R.M.; Webb, W.W. J. Cell Sci., 2000, 113, 3839.

[12] Chow, R.H.; von Rüden, L. (1995) In Single channel recording; Sakmann, Neher, Eds.; Plenum Press, New York, 1995; 245-276. 
[13] Sulzer, D.; Pothos, E.N. Rev. Neurosci., 2000, 11, 159.

[14] Torres, G.E.; Gainetdinov, R.R.; Caron, M.G. Nat. Rev. Neurosci., 2003, 4, 13.

[15] Jones, S.R.; Gainetdinov, R.R.; Jaber, M.; Giros, B.; Wightman, R.M.; Caron, M.G. Proc. Natl. Acad Sci. USA, 1998, 95, 4029.

[16] Benoit-Marand, M.; Jaber, M.; Gonon, F. Eur. J. Neurosci., 2000, 12, 2985.

[17] Schonn, J.S.; Desnos, C.; Henry, J.P.; Darchen, F. J. Neurochem., 2003, 84, 669 .

[18] Ingram, S.L.; Prasad, B.M.; Amara, S.G. Nat. Neurosci., 2002, 5, 971.

[19] Khoshbouei, H.; Wang, H.; Lechleiter, J.D.; Javitch, J.A.; Galli, A. J. Biol. Chem., 2003, 278, 12070.

[20] Gnegy, M.E.; Khoshbouei, H.; Berg, K.A.; Javitch, J.A.; Clarke, W.P.; Zhang, M.; Galli, A. Mol. Pharmacol., 2004, 66, 137.

[21] Kantor, L.; Hewlett, G.H.; Park, Y.H.; Richardson-Burns, S.M.; Mellon, M.J.; Gnegy, M.E. J. Pharmacol. Exp. Ther., 2001, 297, 1016.

[22] Sulzer, D.; Chen, T.K.; Lau, Y.Y.; Kristensen, H.; Rayport, S.; Ewing, A.G. J. Neurosci., 1995, 15, 4102.

[23] Cooper, J.; Bloom, F.; Roth, R. The biochemical basis of neuropsychopharmacology. Oxford Univ. Press, New York., 1996.

[24] Elsworth, J.D.; Roth, R.H. Exp. Neurol., 1997, 144, 4.

[25] Schwarz, R.D.; Uretsky, N.J.; Bianchine, J.R. J. Neurochem., 1980, 35,1120 .

[26] Lindgren, N.; Goiny, M.; Herrera-Marschitz, M.; Haycock, J.W.; Hokfelt, T.; Fisone, G. Eur. J. Neurosci., 2002, 15, 769.

[27] McKenzie, S.; Marley, P.D. Eur. J. Neurosci., 2002, 15, 1485

[28] Kobori, N.; Waymire, J.C.; Haycock, J.W.; Clifton, G.L.; Dash, P.K. J. Biol. Chem., 2004, 279, 2182.

[29] Ivanova, T.; Beyer, C. J. Neurobiol., 2003, 54, 638.

[30] Schmidt, C.J.; Taylor, V.L.; Abbate, G.M.; Nieduzak, T.R. J. Pharmacol. Exp. Ther., 1991, 256, 230.

[31] Booth, R.G.; Baldessarini, R.J.; Kula, N.S.; Gao, Y.; Zong, R.; Neumeyer, J.L. Mol. Pharmacol., 1990, 38, 92.

[32] Hirata, Y.; Nagatsu, T. Brain. Res., 1985, 337, 193.

[33] O'Hara, C.M.; Uhland-Smith, A.; O'Malley, K.L.; Todd, R.D. J. Pharmacol. Exp. Ther., 1996, 277, 186.

[34] Hakansson, K.; Pozzi, L.; Usiello, A.; Haycock, J.; Borrelli, E.; Fisone, G. Eur. J. Neurosci., 2004, 20, 1108.

[35] Mosharov, E.V.; Gong, L.W.; Khanna, B.; Sulzer, D.; Lindau, M. J. Neurosci., 2003, 23, 5835 .

[36] Pothos, E.N.; Mosharov, E.; Liu, K.P.; Setlik, W.; Haburcak, M.; Baldini, G.; Gershon, M.D.; Tamir, H.; Sulzer, D. J. Physiol. 2002, 542, 453.

[37] Pothos, E.N.; Desmond, M.; Sulzer, D. J. Neurochem. 1996, 66, 629.

[38] Pothos, E.N.; Davila, V.; Sulzer, D. J. Neurosci., 1998, 18, 4106

[39] Pothos, E.N.; Przedborski, S.; Davila, V.; Schmitz, Y.; Sulzer, D. J. Neurosci., 1998, 18, 5575 .

[40] Toru, M; Nishikawa, T.; Mataga, N.; Takashima, M. J. Neural. Transm., 1982, 54, 181.

[41] Nishii, K.; Matsushita, N.; Sawada, H.; Sano, H.; Noda, Y.; Mamiya, T.; Nabeshima, T.; Nagatsu, I.; Hata, T.; Kiuchi, K.; Yoshizato, H.; Nakashima, K.; Nagatsu, T.; Kobayashi, K. J. Neurosci. Res., 1998, 54, 450.

[42] Blandini, F. Exp. Neurol., 2003, 184, 556.

[43] Sidhu, A.; Wersinger, C.; Vernier, P. FASEB J., 2004, 18, 637.

[44] Abeliovich, A.; Schmitz, Y.; Farinas, I.; Choi-Lundberg, D.; Ho, W.H.; Castillo, P.E.; Shinsky, N.; Verdugo, J.M.; Armanini, M.; Ryan, A.; Hynes, M.; Phillips, H.; Sulzer, D.; Rosenthal, A. Neuron, 2000, 25, 239.

[45] Stefanis, L.; Larsen, K.E.; Rideout, H.J.; Sulzer, D.; Greene, L.A. J. Neurosci., 2001, 21, 9549 .

[46] Cabin, D.E.; Shimazu, K.; Murphy, D.; Cole, N.B.; Gottschalk, W.; McIlwain, K.L.; Orrison, B.; Chen, A.; Ellis, C.E.; Paylor, R.; Lu, B.; Nussbaum, R.L. J. Neurosci., 2002, 22, 8797.

[47] Youdim, M.B.; Weinstock, M. Neurotoxicology, 2004, 25, 243.

[48] Cases, O.; Seif, I.; Grimsby, J.; Gaspar, P.; Chen, K.; Pournin, S.; Müller, U.; Aguet, M.; Babinet, C.; Shih, J.C.; De Maeyer, E. Science, 1995, 268, 1763.

[49] Chen, K.; Holschneider, D.P.; Wu, W.; Rebrin, I.; Shih, J.C. J. Biol. Chem., 2004, 279, 39645.

[50] Ahnert-Hilger, G.; Holtje, M.; Pahner, I.; Winter, S.; Brunk, I. Rev. Physiol. Biochem. Pharmacol., 2003, 150, 140.
[51] Fleckenstein, A.E.; Hanson, G.R. Eur. J. Pharmacol., 2003, 479, 283.

[52] Miller, G.W.; Erickson, J.D.; Perez, J.T.; Penland, S.N.; Mash D.C.; Rye, D.B.; Levey, A.I. Exp. Neurol., 1999, 156, 138.

[53] Little, K.Y.; Krolewski, D.M.; Zhang, L.; Cassin, B.J. Am. J. Psychiatry, 2003, 160, 47.

[54] Takahashi, N.; Miner, L.L.; Sora, I.; Ujike, H.; Revay, R.S.; Kostic V.; Jackson-Lewis, V.; Przedborski, S.; Uhl, G.R. Proc. Natl. Acad. Sci. USA, 1997, 94, 9938.

[55] German, D.C.; Liang, C.L.; Manaye, K.F.; Lane, K.; Sonsalla, P.K. Neuroscience, 2000, 101, 1063.

[56] Reinhard, J.F.Jr.; Diliberto, E.J.Jr.; Viveros, O.H.; Daniels, A.J. Proc. Natl. Acad. Sci. USA., 1987, 84, 8160.

[57] Nakanishi, N.; Onozawa, S.; Matsumoto, R.; Kurihara, K.; Ueha, T.; Hasegawa, H.; Minami, N. FEBS Lett., 1995, 368, 411.

[58] Sulzer, D.; Rayport, S. Neuron, 1990, 5, 797.

[59] Brown, J.M.; Hanson, G.R.; Fleckenstein, A.E. J. Neurochem., 2000, 74, 2221.

[60] Hansen, J.P.; Riddle, E.L.; Sandoval, V.; Brown, J.M.; Gibb, J.W.; Hanson, G.R.; Fleckenstein, A.E. J. Pharmacol. Exp. Ther., 2002 300, 1093.

[61] Brown, J.M.; Hanson, G.R.; Fleckenstein, A.E. J. Pharmacol. Exp. Ther., 2001, 298, 1150

[62] Sandoval, V.; Riddle, E.L.; Hanson, G.R.; Fleckenstein, A.E. J. Pharmacol. Exp. Ther, 2003, 304, 1181

[63] Crosby, M.J.; Hanson, J.E.; Fleckenstein, A.E.; Hanson, G.R. Eur J. Pharmacol., 2002, 438, 75.

[64] Truong, J.G.; Hanson, G.R.; Fleckenstein, A.E. Eur. J. Pharmacol., 2004, 492, 143.

[65] Mundorf, M.L.; Troyer, K.P.; Hochstetler, S.E.; Near, J.A.; Wightman, R.M. J. Biol. Chem., 2000, 275, 9136.

[66] Sombers, L.A.; Hanchar, H.J.; Colliver, T.L.; Wittenberg, N.; Cans, A.; Arbault, S.; Amatore, C.; Ewing, A.G. J. Neurosci., 2004, 24, 303.

[67] Gong, L.W.; Hafez, I.; Alvarez de Toledo, G.; Lindau, M. J. Neurosci., 2003, 23, 7917.

[68] Patel, J.; Mooslehner, K.A.; Chan, P.M.; Emson, P.C.; Stamford, J.A. J. Neurochem., 2003, 85, 898

[69] Pothos, E.N.; Larsen, K.E.; Krantz, D.E.; Liu, Y.; Haycock, J.W Setlik, W.; Gershon, M.D.; Edwards, R.H.; Sulzer, D. J. Neurosci., 2000, 20, 7297.

[70] Mundorf, M.L.; Hochstetler, S.E.; Wightman, R.M. J. Neurochem. 1999, 73,2397.

[71] Taupenot, L.; Harper, K.L.; O'Connor, D.T. N. Engl. J. Med. 2003 348, 1134.

[72] Kim, T.; Tao-Cheng, J.H.; Eiden, L.E.; Loh, Y.P. Cell, 2001, 106, 499.

[73] Yoo, S.H. Trends Neurosci., 2000, 23, 424.

[74] Yoo, S.H.; Jeon, C.J. J. Biol.Chem., 2000, 275, 12553

[75] Blondel, O.; Bell, G.I.; Seino, S. Trends Neurosci., 1995, 18, 157.

[76] Gibson, C.J.; Munoz, D.G. J. Neural. Transm., 1998, 105, 1083.

[77] Fasciotto, B.H.; Trauss, C.A.; Greeley, G.H.; Cohn, D.V. Endocrinology, 1993, 133, 461.

[78] Russell, J.; Gee, P.; Liu, S.M.; Angeletti, R.H. Endocrinology, 1994, 135, 337.

[79] Sanchez-Margalet, V.; Gonzalez-Yanes, C.; Santos-Alvarez, J.; Najib, S. Adv. Exp. Med. Biol., 2000, 482, 247.

[80] Galindo, E.; Mendez, M.; Calvo, S.; Gonzalez-Garcia, C.; Cena, V.; Hubert, P.; Bader, M.F.; Aunis, D. J. Biol. Chem., 1992, 267, 407.

[81] Mahata, S.K.; Mahata, M.; Parmer, R.J.; O’Connor, D.T. J. Biol. Chem., 1999, 274, 2920.

[82] Taupenot, L.; Mahata, S.K.; Mahata, M.; Parmer, R.J.; O'Connor, D.T. Regul. Pept., 2000, 95, 9.

[83] Wiedermann, C.J. Peptides, 2000, 21, 1289.

[84] O’Connor, D.T.; Cervenka, J.H.; Stone, R.A.; Parmer, R.J.; FrancoBourland, R.E.; Madrazo, I.; Langlais, P.J. Neuroscience, 1993, 56, 999.

[85] Woulfe, J.; Deng, D.; Munoz, D. Neuropeptides, 1999, 33, 285.

[86] Munoz, D.G. Lab. Invest., 1991, 64, 826.

[87] Yasuhara, O.; Kawamata, T.; Aimi, Y.; McGeer, E.G.; McGeer, P.L. Neurosci. Lett., 1994, 170, 13.

[88] Iwazaki, T.; Shibata, I.; Niwa, S.; Matsumoto, I. Neurosci. Lett., 2004, 367, 293. 
[89] Hilfiker, S.; Pieribone, V.A.; Czernik, A.J.; Kao, H.T.; Augustine, G.J.; Greengard, P. Philos. Trans. Royal. Soc. Lond. Biol. Sci., 1999, 354, 269.

[90] Humeau, Y.; Doussau, F.; Vitiello, F.; Greengard, P.; Benfenati, F.; Poulain, B. J. Neurosci., 2001, 21, 4195.

[91] Trifaró, J.M.; Lejen, T.; Rose, S.D.; Pene, T.D.; Barkar, N.D.; Seward, E.P. Neurochem. Res., 2002, 27, 1371.

[92] Li, L.; Chin, L.S.; Shupliakov, O.; Brodin, L.; Sihra, T.S.; Hvalby, O.; Jensen, V.; Zheng, D.; McNamara, J.O.; Greengard, P.; Andersen, P. Proc. Natl. Acad. Sci. USA, 1995, 92, 9235.

[93] Rosahl, T.W.; Spillane, D.; Missler, M.; Herz, J.; Selig, D.K.; Wolff, J.R.; Hammer, R.E.; Malenka, R.C.; Südhof, T.C. Nature, 1995, 375, 488.

[94] Zhang, L.; Marcu, M.G.; Nau-Staudt, K.; Trifaró, J.M. Neuron, 1996, 17, 287.

[95] Lejen, T.; Skolnik, K.; Rose, S.D.; Marcu, M.G.; Elzagallaai, A.; Trifaró, J.M., J. Neurochem., 2001, 76, 768.

[96] Gil, A.; Rueda, J.; Viniegra, S.; Gutierrez, L.M. Neuroscience, 2000, 98,605

[97] Staal, R.G.W.; Mosharov, E.V.; Sulzer, D. Nat. Neurosci., 2004, 7, 341.

[98] Cuchillo-Ibanez, I.; Lejen, T.; Albillos, A.; Rose, S.D.; Olivares, R.; Villarroya, M.; Garcia, A.G.; Trifaró, J.M. J. Phsyiol., 2004, $560,63$.

[99] Eitzen, G. Biochim. Biophys. Acta, 2003, 1641, 175

[100] Ñeco, P.; Giner, D.; del Mar Frances, M.; Viniegra, S.; Gutierrez, L.M. Eur. J. Neurosci., 2003, 18, 733 .

[101] Ñeco, P.; Giner, D.; Viniegra, S.; Borges, R.; Villarroel, A.; Gutierrez, L.M. J. Biol. Chem., 2004, 279, 27450.

[102] Burgoyne, R.D.; Morgan, A. Physiol. Rev., 2003, 83, 581.

[103] Jahn, R.; Lang, T.; Südhof, T.C. Cell, 2003, 112, 519.

[104] Li, L.; Chin, L.S. Cell. Mol. Life Sci., 2003, 60, 942.

[105] Sollner, T.H. Mol. Membr. Biol., 2003, 20, 209.

[106] Schiavo, G.; Matteoli, M.; Montecucco, C. Physiol. Rev., 2000, 80, 717.

[107] Gil, A.; Viniegra, S.; Gutierrez, L.M. Eur. J. Neurosci., 1998, 10, 3369.

[108] Xu, T.; Binz, T.; Niemann, H.; Neher, E. Nat. Neurosci., 1998, 1 , 192.

[109] Graham, M.E.; Fisher, R.J.; Burgoyne, R.D. Biochimie, 2000, 82, 469.

[110] Comella, C.L.; Pullman, S.L. Muscle Nerve, 2004, 29, 628.

[111] Rizo, J.; Südhof, T.C. Nat. Rev. Neurosci., 2002, 3, 641.

[112] Voets, T.; Toonen, R.F.; Brian, E.C.; de Wit, H.; Moser, T.; Rettig, J.; Südhof, T.C.; Neher, E.; Verhage, M. Neuron, 2001, 31, 581.

[113] Fisher, R.J.; Pevsner, J.; Burgoyne, R.D. Science, 2001, 291, 875.

[114] Graham, M.E.; Barclay, J.W.; Burgoyne, R.D. J. Biol. Chem., 2004, 279, 32751 .

[115] Barclay, J.W.; Craig, T.J.; Fisher, R.J.; Ciufo, L.F.; Evans, G.J.; Morgan, A.; Burgoyne, R.D. J. Biol. Chem., 2003, 278, 10538.

[116] Barclay, J.W.; Aldea, M.; Craig, T.J.; Morgan, A.; Burgoyne, R.D. J. Biol. Chem., 2004, 279, 41495 .

[117] Silinsky, E.M.; Searl, T.J. Br. J. Pharmacol., 2003, 138, 1191.

[118] Varoqueaux, F.; Sigler, A.; Rhee, J.S.; Brose, N.; Enk, C.; Reim, K.; Rosenmund, C. Proc. Natl. Acad. Sci. USA, 2002, 99, 9037.

[119] Ashery, U.; Varoqueaux, F.; Voets, T.; Betz, A.; Thakur, P.; Koch, H.; Neher, E.; Brose, N.; Rettig, J. EMBO J., 2000, 19, 3586.

[120] Wassenberg, J.J.; Martin, T.F. Ann. N.Y. Acad. Sci., 2002, 971, 201.

[121] Elhamdani, A.; Martin, T.F.; Kowalchyk, J.A.; Artalejo, C.R. J. Neurosci., 1999, 19, 7375 .

[122] Grishanin, R.N.; Kowalchyk, J.A.; Klenchin, V.A.; Ann, K.; Earles, C.A.; Chapman, E.R; Gerona, R.R.; Martin, T.F. Neuron, 2004, 43, 551 .

[123] Koh, T.W.; Bellen, H.J. Trends Neurosci., 2003, 26, 413.

[124] Bai, J.; Chapman, E.R. Trends Biochem. Sci., 2004, 29, 143.

[125] Fernandez-Chacon, R.; Konigstorfer, A.; Gerber, S.H.; Garcia, J.; Matos, M.F.; Stevens, C.F.; Brose, N.; Rizo, J.; Rosenmund, C.; Südhof, T.C. Nature, 2001, 410, 41

[126] Voets, T.; Moser, T.; Lund, P.E.; Chow, R.H.; Geppert, M.; Südhof, T.C.; Neher, E. Proc. Natl. Acad. Sci. USA, 2001, 98, 11680 .

[127] Sorensen, J.B.; Fernandez-Chacon, R.; Südhof, T.C.; Neher, E. J. Gen. Physiol., 2003, 122, 265.

[128] Marz, K.E.; Hanson, P.I. Trends Neurosci., 2002, 25, 381
[129] Glynn, D.; Bortnick, R.A.; Morton, A.J. Hum. Mol. Genet., 2003, 12, 2431.

[130] Freeman, W.; Morton, A.J. Brain Res. Bull., 2004, 63, 45

[131] Morton, A.J.; Faull, R.L.; Edwardson, J.M. Brain Res. Bull., 2001, $56,111$.

[132] Edwardson, J.M.; Wang, C.T.; Gong, B.; Wyttenbach, A.; Bai, J.; Jackson, M.B.; Chapman, E.R.; Morton, A.J. J. Biol. Chem., 2003, 278,30849

[133] Archer, D.A.; Graham, M.E.; Burgoyne, R.D. J. Biol. Chem., 2002 277, 18249.

[134] Kibble, A.V.; Barnard, R.J.; Burgoyne, R.D. J. Cell Sci., 1996, 109 2417

[135] Xu, T.; Ashery, U.; Burgoyne, R.D.; Neher, E. EMBO J., 1999, 18 , 3293.

[136] Xu, J.; Xu, Y.; Ellis-Davies, G.C.; Augustine, G.J.; Tse, F.W. J. Neurosci., 2002, 22, 53.

[137] Graham, M.E.; Burgoyne, R.D. J. Neurosci., 2000, 20, 1281

[138] Swope, S.L.; Moss, S.J.; Raymond, L.A.; Huganir, R.L. Adv Second Messenger Phosphoprotein Res., 1999, 33, 49.

[139] Page, G.; Barc-Pain, S.; Pontcharraud, R.; Cante, A.; Piriou, A.; Barrier, L. Neurochem. Int., 2004, 45, 627.

[140] Borges, R.; Machado, J.D.; Betancor, G.; Camacho, M. Ann. N.Y. Acad. Sci., 2002, 971, 184

[141] Sim, A.T.; Baldwin, M.L.; Rostas, J.A.; Holst, J.; Ludowyke, R.I. Biochem. J., 2003, 373, 641 .

[142] Evans, G.J.; Morgan, A. Biochem. Soc. Trans., 2003, 31, 824

[143] Baldelli, P.; Hernandez-Guijo, J.M.; Carabelli, V.; Novara, M. Cesetti, T.; Andres-Mateos, E.; Montiel, C.; Carbone, E. Mol. Neurobiol., 2004, 29, 73.

[144] Zhu, G.; Okada, M.; Yoshida, S.; Hirose, S.; Kaneko, S. Neurosci. Lett., 2004, 363, 120

[145] Nagy, G.; Reim, K.; Matti, U.; Brose, N.; Binz, T.; Rettig, J.; Neher, E.; Sorensen, J.B. Neuron, 2004, 41, 417

[146] Machado, J.D.; Morales, A.; Gomez, J.F.; Borges, R. Mol. Pharmacol., 2001, 60, 514

[147] Koga, T.; Takahashi, M. Neurosci. Lett., 2004, 360, 145.

[148] Misonou, H.; Ohara-Imaizumi, M.; Murakami, T.; Kawasaki, M.; Ikeda, K.; Wakai, T.; Kumakura, K. Cell. Mol. Neurobiol., 1998 $18,379$.

[149] Taylor, S.C.; Green, K.N.; Carpenter, E.; Peers, C. J. Biol. Chem., 2000, 275,26786

[150] Soliakov, L.; Wonnacott, S. Br. J. Pharmacol., 2001, 132, 785.

[151] Westerink, R.H.S.; Klompmakers, A.A.; Westenberg, H.G.M.; Vijverberg, H.P.M. Brain Res., 2002, 957, 25.

[152] Sena, C.M.; Tome, A.R.; Santos, R.M.; Rosario, L.M. FEBS Lett., 1995, 359, 137 .

[153] Shoji-Kasai, Y.; Itakura, M.; Kataoka, M.; Yamamori, S.; Takahashi, M. Eur. J. Neurosci., 2002, 15, 1390.

[154] Yang, H.; Wang, X.; Sumners, C.; Raizada, M.K. Hypertension 2002, 39, 567.

[155] Giambalvo, C.T. Synapse, 2004, 51, 128

[156] Nair, S.G.; Gudelsky, G.A. Brain Res., 2004, 1013, 168

[157] Schweitzer, E.S.; Sanderson, M.J.; Wasterlain, C.G. J. Cell Sci., 1995, 108, 2619.

[158] Maurer, J.A.; Wenger, B.W.; McKay, D.B. J. Neurochem., 1996, 66, 105.

[159] Novak, G.; Seeman, P.; Tallerico, T. Brain Res. Mol. Brain Res., 2000, 82,95 .

[160] Iwata, S.I.; Hewlett, G.H.; Ferrell, S.T.; Kantor, L.; Gnegy, M.E. J. Pharmacol. Exp. Ther., 1997, 283, 1445.

[161] Burgoyne, R.D.; Clague, M.J. Biochim. Biophys. Acta, 2003, 1641 , 137.

[162] Quetglas, S.; Iborra, C.; Sasakawa, N.; De Haro, L.; Kumakura, K.; Sato, K.; Leveque, C.; Seagar, M. EMBO J., 2002, 21, 3970.

[163] Staal, R.G.; Mosharov, E.; Sulzer, D. Ann. N.Y. Acad. Sci., 2002 971,269

[164] Turner, K.M.; Burgoyne, R.D.; Morgan, A. Trends Neurosci., 1999, 22, 459.

[165] Gutierrez, L.M.; Quintanar, J.L.; Rueda, J.; Viniegra, S.; Reig, J.A. Eur. J. Cell Biol., 1995, 68, 88.

[166] Berridge, M.J. Neuron, 1998, 21, 13

[167] Rettig, J.; Neher, E. Science, 2002, 298, 781

[168] Zucker, R.S.; Regehr, W.G. Annu. Rev. Physiol., 2002, 64, 355.

[169] Catterall, W.A. Cell Calcium, 1998, 24, 307.

[170] Catterall, W.A. Ann. N.Y. Acad. Sci., 1999, 868, 144. 
[171] Kits, K.S.; Mansvelder, H.D. Brain Res. Brain Res. Rev., 2000, 33, 78.

[172] Fisher, T.E.; Bourque, C.W. Prog. Biophys. Mol. Biol., 2001, 77, 269.

[173] Cuchillo-Ibanez, I.; Albillos, A.; Aldea, M.; Arroyo, G.; Fuentealba, J.; Garcia, A.G. Ann. N.Y. Acad. Sci., 2002, 971, 108.

[174] Albillos, A.; Neher, E.; Moser, T. J. Neurosci., 2000, 20, 8323.

[175] Taylor, S.C.; Peers, C. J. Neurochem., 1999, 73, 874.

[176] Green, K.N.; Taylor, S.C.; Smith, I.F.; Peers, C. Neurosci. Lett., 2001, 301, 13 .

[177] Gandia, L.; Mayorgas, I.; Michelena, P.; Cuchillo, I.; de Pascual, R.; Abad, F.; Novalbos, J.M.; Larranaga, E.; Garcia, A.G. Pflugers Arch., 1998, 436, 696.

[178] Villarroya, M.; Olivares, R.; Ruiz, A.; Cano-Abad, M.F.; de Pascual, R.; Lomax, R.B.; Lopez, M.G.; Mayorgas, I.; Gandia, L.; Garcia, A.G. J. Physiol., 1999, 516, 421.

[179] Bournaud, R.; Hidalgo, J.; Yu, H.; Jaimovich, E.; Shimahara, T. J. Physiol., 2001, 537, 35 .

[180] Elhamdani, A.; Palfrey, C.H.; Artalejo, C.R. Neurobiol. Aging, 2002, 23, 287.

[181] Turner, T.J.; Adams, M.E.; Dunlap, K. Proc. Natl. Acad. Sci. USA, 1993, 90, 9518.

[182] Carvalho, C.M.; Ferreira, I.L.; Duarte, C.B.; Malva, J.O.; Tretter, L.; Adam-Vizi, V.; Carvalho, A.P. Brain Res., 1995, 669, 234.

[183] de Erausquin, G.; Brooker, G.; Hanbauer, I. Neurosci. Lett., 1992, $145,121$.

[184] Bergquist, F.; Jonason, J.; Pileblad, E.; Nissbrandt, H. J. Neurochem., 1998, 70, 1532.

[185] Bergquist, F.; Nissbrandt, H. Neuroscience, 2003, 120, 757.

[186] Okita, M.; Watanabe, Y.; Taya, K.; Utsumi, H.; Hayashi, T. Physiol. Behav., 2000, 68, 641.

[187] Ogura, H.; Furuya, Y.; Teramoto, T.; Niidome, T.; Nishizawa, Y.; Yamanishi, Y. Peptides, 1998, 19, 1017.

[188] Mena, M.A.; Garcia de Yebenes, M.J.; Tabernero, C.; Casarejos, M.J.; Pardo, B.; Garcia de Yebenes, J. Clin. Neuropharmacol., 1995, 18,410 .

[189] Offen, D.; Halevi, S.; Orion, D.; Mosberg, R.; Stern-Goldberg, H.; Melamed, E.; Atlas, D. Neurology, 1998, 51, 1100.

[190] Carbone, E.; Carabelli, V.; Cesetti, T.; Baldelli, P.; HernandezGuijo, J.M.; Giusta, L. Pflugers Arch., 2001, 442, 801.

[191] Kleppisch, T.; Ahnert-Hilger, G.; Gollasch, M.; Spicher, K.; Hescheler, J.; Schultz, G.; Rosenthal, W. Pflugers Arch., 1992, $421,131$.

[192] Hernandez-Guijo, J.M.; Carabelli, V.; Gandia, L.; Garcia, A.G.; Carbone, E. Eur. J. Neurosci., 1999, 11, 3574.

[193] Drolet, P.; Bilodeau, L.; Chorvatova, A.; Laflamme, L.; GalloPayet, N.; Payet, M.D. Mol. Endocrinol., 1997, 11, 503.

[194] Surmeier, D.J.; Bargas, J.; Hemmings, H.C.Jr.; Nairn, A.C.; Greengard, P. Neuron, 1995, 14, 385.

[195] Wolfe, S.E.; Morris, S.J. J. Neurochem., 1999, 73, 2375.

[196] Hernandez-Lopez, S.; Tkatch, T.; Perez-Garci, E.; Galarraga, E.; Bargas, J.; Hamm, H.; Surmeier, D.J. J. Neurosci., 2000, $20,8987$.

[197] Bigornia, L.; Allen, C.N.; Jan, C.R.; Lyon, R.A.; Titeler, M.; Schneider, A.S. J. Pharmacol. Exp. Ther., 1990, 252, 586.

[198] Kuzhikandathil, E.V.; Oxford, G.S. J. Neurosci., 1999, 19, 1698.

[199] Artalejo, C.R.; Ariano, M.A.; Perlman, R.L.; Fox, A.P. Nature, 1990, 348, 239.

[200] Hernandez-Lopez, S.; Bargas, J.; Surmeier, D.J.; Reyes, A.; Galarraga, E. J. Neurosci., 1997, 17, 3334.

[201] Oldham, S.B.; Ritchie, T.; Noble, E.P. Alcohol Alcohol., 1989, 24, 43.

[202] Kress, H.G.; Muller, J.; Eisert, A.; Gilge, U.; Tas, P.W.; Koschel, K. Anesthesiology, 1991, 74, 309.

[203] Hirota, K.; Kudo, M.; Kudo, T.; Kitayama, M.; Kushikata, T.; Lambert, D.G.; Matsuki, A. Neurosci. Lett., 2000, 291, 175.

[204] Hirota, K.; Kudo, M.; Kudo, T.; Matsuki, A.; Lambert, D.G. Br. J. Anaesth. 2000, 85, 874.

[205] Tyler, W.J.; Perrett, S.P.; Pozzo-Miller, L.D. Neuroscientist, 2002, 8,524 .

[206] Elhamdani, A.; Brown, M.E.; Artalejo, C.R.; Palfrey, H.C. J. Neurosci., 2000, 20, 2495.

[207] Wang, J.; Chen, G.; Lu, B.; Wu, C.P. Neurosignals, 2003, 12, 78.

[208] Atlas, D. J. Neurochem., 2001, 77, 972.

[209] Spafford, J.D.; Zamponi, G.W. Curr. Opin. Neurobiol., 2003, 13, 308.
[210] Cohen, R.; Elferink, L.A.; Atlas, D. J. Biol. Chem., 2003, 278, 9258.

[211] Taylor, S.C.; Peers, C. J. Physiol., 1999, 514, 483.

[212] Green, K.N.; Boyle, J.P.; Peers, C. J. Physiol., 2002, 541, 1013.

[213] Green, K.N.; Peers, C. J. Neurochem., 2002, 81, 1043.

[214] Keating, D.J.; Rychkov, G.Y.; Adams, M.B.; Holgert, H.; McMillen, I.C.; Roberts, M.L. J. Physiol., 2004, 555, 489.

[215] Tse, F.W.; Tse, A. Bioessays, 1999, 21, 861.

[216] Finnegan, J.M.; Wightman, R.M. J. Biol. Chem., 1995, 270, 5353.

[217] Pan, C.Y.; Fox, A.P. J. Neurochem., 2000, 75, 1132.

[218] Morikawa, H.; Imani, F.; Khodakhah, K.; Williams, J.T. J. Neurosci., 2000, 20, RC103.

[219] Ohta, T.; Wakade, A.R.; Yonekubo, K.; Ito, S. Neurosci. Lett., 2002, 326, 167.

[220] Liu, P.S.; Lin, Y.J.; Kao, L.S. J. Neurochem., 1991, 56, 172.

[221] Wan, K.; Moriya, T.; Akiyama, M.; Takeshima, H.; Shibata, S. Biochem. Biophys. Res. Commun., 1999, 266, 588.

[222] Seutin, V.; Mkahli, F.; Massotte, L.; Dresse, A. J. Neurophysiol., 2000, 83, 192.

[223] Fomina, A.F.; Nowycky, M.C. J. Neurosci., 1999, 19, 3711.

[224] Parekh, A.B.; Penner, R. Physiol. Rev., 1997, 77, 901.

[225] Putney, J.W.Jr.; Broad, L.M.; Braun, F.J.; Lievremont, J.P.; Bird, G.S. J. Cell. Sci., 2001, 114, 2223.

[226] Parekh, A.B. J. Physiol., 2003, 547, 333.

[227] Montero, M.; Alonso, M.T.; Carnicero, E.; Cuchillo-Ibanez, I.; Albillos, A.; Garcia, A.G.; Garcia-Sancho, J.; Alvarez, J. Nat. Cell. Biol., 2000, 2, 57.

[228] Montero, M.; Alonso, M.T.; Albillos, A.; Cuchillo-Ibanez, I.; Olivares, R.; Villalobos, C.; Alvarez, J. Biochem. J., 2002, 365, 451.

[229] Yang, D.M.; Kao, L.S. J. Neurochem., 2001, 76, 210.

[230] Duarte, E.P.; Baltazar, G.; Carvalho, A.P. Eur. J. Neurosci., 1994, 6, 1128.

[231] Kao, L.S.; Schneider, A.S. J. Biol. Chem., 1986, 261, 4881.

[232] Tang, Y.M.; Travis, E.R.; Wightman, R.M.; Schneider, A.S. $J$. Neurochem., 2000, 74, 702.

[233] Marley, P.D.; Bales, P.J.; Zerbes, M.; Powis, D.A.; O'Farrell, M. J. Neurochem., 2000, 75, 1162.

[234] Miller, R.J. Prog. Neurobiol., 1991, 37, 255.

[235] Airaksinen, M.S.; Eilers, J.; Garaschuk, O.; Thoenen, H.; Konnerth, A.; Meyer, M. Proc. Natl. Acad. Sci. USA, 1997, 94, 1488.

[236] Nägerl, U.V.; Mody, I.; Jeub, M.; Lie, A.A.; Elger, C.E.; Beck, H. J. Neurosci., 2000, 20, 1831 .

[237] Barski, J.J.; Hartmann, J.; Rose, C.R.; Hoebeek, F.; Morl, K.; NollHussong, M.; De Zeeuw, C.I.; Konnerth, A.; Meyer, M. J. Neurosci., 2003, 23, 3469.

[238] Feng, L.; Wang, C.Y.; Jiang, H.; Oho, C.; Mizuno, K.; DugichDjordjevic, M.; Lu, B. Brain Res. Mol Brain Res., 1999, 66, 62.

[239] Appel, S.H.; Beers, D.; Siklos, L.; Engelhardt, J.I.; Mosier, D.R. Amyotroph Lateral Scler Other Motor Neuron Disord., 2001, 2 Suppl 1, S47.

[240] Burgoyne, R.D.; Weiss, J.L. Biochem. J., 2001, 353, 1

[241] Hilfiker, S. Biochem. Soc. Trans., 2003, 31, 828.

[242] Rousset, M.; Cens, T.; Gavarini, S.; Jeromin, A.; Charnet, P. J. Biol. Chem., 2003, 278, 7019.

[243] Pan, C.Y.; Jeromin, A.; Lundstrom, K.; Yoo, S.H.; Roder, J.; Fox, A.P. J. Neurosci., 2002, 22, 2427.

[244] McFerran, B.W.; Weiss, J.L.; Burgoyne, R.D. J. Biol. Chem., 1999, $274,30258$.

[245] Taverna, E.; Francolini, M.; Jeromin, A.; Hilfiker, S.; Roder, J.; Rosa, P. J. Cell Sci., 2002, 115, 3909.

[246] Sippy, T.; Cruz-Martin, A.; Jeromin, A.; Schweizer, F.E. Nat. Neurosci., 2003, 6, 1031.

[247] Kabbani, N.; Negyessy, L.; Lin, R.; Goldman-Rakic, P.; Levenson, R. J. Neurosci., 2002, 22, 8476.

[248] Valtorta, F.; Meldolesi, J.; Fesce, R. Trends Cell Biol., 2001, 11, 324.

[249] Morgan, J.R.; Augustine, G.J.; Lafer, E.M. Neuromolecular Med., 2002, 2, 101 .

[250] Royle, S.J.; Lagnado, L. J. Physiol., 2003, 553, 345.

[251] Gundelfinger, E.D.; Kessels, M.M.; Qualmann, B. Nature Rev. Mol. Cell Biol., 2003, 4, 127.

[252] Heuser, J.E.; Reese, T.S. J. Cell Biol., 1973, 57, 315.

[253] Ceccarelli, B.; Hurlbut, W.P.; Mauro, A. J.Cell Biol., 1973, 57, 499. 
[254] Lindau, M.; Alvarez de Toledo, G. Biochim. Biophys. Acta, 2003, 1641, 167.

[255] Bauer, R.A.; Khera, R.S.; Lieber, J.L.; Angleson, J.K. FEBS Lett., 2004, 571, 107.

[256] Krupa, B.; Liu, G. Trends Neurosci., 2004, 27, 62

[257] Ales, E.; Tabares, L.; Poyato, J M.; Valero, V.; Lindau, M.; Alvarez de Toledo, G. Nat. Cell Biol., 1999, 1, 40.

[258] Stevens, C.F.; Williams, J.H. Proc. Natl. Acad. Sci. USA, 2000, 97, 12828

[259] Cousin, M.A.; Robinson, P.J. J. Neurochem., 2000, 75, 1645.

[260] Aravanis, A.M.; Pyle, J.L.; Tsien, R.W. Nature, 2003, 423, 643.

[261] Gandhi, S.P.; Stevens, C.F. Nature, 2003, 423, 607.

[262] Graham, M.E.; O'Callaghan, D.W.; McMahon, H.T.; Burgoyne, R.D. Proc. Natl. Acad. Sci. USA, $2002,99,7124$.

[263] Wang, C.T.; Lu, J.C.; Bai, J.; Chang, P.Y.; Martin, T.F.; Chapman, E.R.; Jackson, M.B. Nature, 2003, 424, 943.

[264] Bai, J.; Wang, C.T.; Richards, D.A.; Jackson, M.B.; Chapman, E.R. Neuron, 2004, 41, 929.

[265] Holroyd, P.; Lang, T.; Wenzel, D.; De Camilli, P.; Jahn, R. Proc. Natl. Acad. Sci. USA, 2002, 99, 16806.

[266] Artalejo, C.R.; Elhamdani, A.; Palfrey, H.C. Proc. Natl. Acad. Sci. USA, 2002, 99, 6358.

[267] Greene, L.A.; Rein, G. Brain Res., 1977, 129, 247.

[268] Jia, M.; Li, M.X.; Liu, X.W.; Jiang, H.; Nelson, P.G.; Guroff, G. J. Neurophysiol., 1999, 82, 2847.

[269] Zerby, S.E.; Ewing, A.G. Brain Res., 1996, 712, 1.

[270] Amino, S.; Itakura, M.; Ohnishi, H.; Tsujimura, J.; Koizumi, S.; Takei, N.; Takahashi, M. J. Biochem., 2002, 131, 887.

[271] Rostene, W.; Sarrieau, A.; Nicot, A.; Scarceriaux, V.; Betancur, C.; Gully, D.; Meaney, M.; Rowe, W.; De Kloet, R.; Pelaprat, D.; Berod, A.. J. Psychiatry Neurosci., 1995, 20, 349.

[272] Czyrak, A.; Mackowiak, M.; Chocyk, A.; Fijal, K.; Wedzony, K. Pol. J. Pharmacol., 2003, 55, 667.

[273] Tischler, A.S.; Perlman, R.L.; Morse, G.M.; Sheard, B.E. J. Neurochem., 1983, 40, 364.

[274] Westerink, R.H.S.; Vijverberg, H.P.M. J. Neurochem., 2002, 80, 861.

[275] Piazza, P.V.; Barrot, M.; Rouge-Pont, F.; Marinelli, M.; Maccari, S.; Abrous, D.N.; Simon, H.; Le Moal, M. Proc. Natl. Acad. Sci. USA, 1996, 93, 15445

[276] Marinelli, M.; Aouizerate, B.; Barrot, M.; Le Moal, M.; Piazza, P.V. Proc. Natl. Acad. Sci. USA, 1998, 95, 7742.

[277] Shulman, L.M. Parkinsonism Relat. Disord., 2002, 8, 289.

[278] Becker, J.B. Synapse, 1990, 5, 157.

[279] Dluzen, D.E.; Anderson, L.I. Neurosci. Lett., 1997, 230, 140.

[280] Disshon, K.A.; Dluzen, D.E. Brain Res., 2000, 868, 95.

[281] Creutz, L.M.; Kritzer, M.F. J. Comp. Neurol., 2002, 446, 288.

[282] Beyer, C.; Raab, H. Eur. J. Neurosci., 1998, 10, 255.

[283] Machado, J.D.; Alonso, C.; Morales, A.; Gomez, J.F.; Borges, R. J. Pharmacol. Exp. Ther., 2002, 301, 631.

[284] Kelly, M.J.; Qiu, J.; Ronnekleiv, O.K. Ann. N.Y. Acad. Sci., 2003, 1007,6

[285] Altar, C.A.; Cai, N.; Bliven, T.; Juhasz, M.; Conner, J.M.; Acheson, A.L.; Lindsay, R.M.; Wiegand, S.J. Nature, 1997, 389, 856.

[286] Guillin, O.; Diaz, J.; Carroll, P.; Griffon, N.; Schwartz, J.C.; Sokoloff, P. Nature, 2001, 411, 86.

[287] Goggi, J.; Pullar, I.A.; Carney, S.L.; Bradford, H.F. Brain Res., 2002, 941, 34

[288] Salvatore, M.F.; Zhang, J.L.; Large, D.M.; Wilson, P.E.; Gash, C.R.; Thomas, T.C.; Haycock, J.W.; Bing, G.; Stanford, J.A.; Gash, D.M.; Gerhardt, G.A. J. Neurochem.,2004, 90, 245.

[289] Bourque, M.J.; Trudeau, L.E. Eur. J. Neurosci., 2000, 12, 3172.
[290] Zurn, A.D.; Widmer, H.R.; Aebischer, P. (2001). Brain Res. Brain Res. Rev., 2001, 36, 222

[291] Gouhier, C.; Chalon, S.; Aubert-Pouessel, A.; Venier-Julienne, M.C.; Jollivet, C.; Benoit, J.P.; Guilloteau, D. Synapse, 2002, 44 124.

[292] Tilson, H.A.; Kodavanti, P.R. Neurotoxicology, 1998, 19, 517

[293] Choksi, N.Y.; Kodavanti, P.R.; Booth, R.G. Fundam. Appl. Toxicol., 1997, 39, 76.

[294] Mariussen, E.; Fonnum, F. Toxicology, 2001, 159, 11

[295] Inglefield, J.R.; Mundy, W.R.; Shafer, T.J. J. Pharmacol. Exp. Ther., 2001, 297, 762.

[296] Bemis, J.C.; Seegal, R.F. Toxicol. Sci., 2004, 80, 288

[297] Westerink, R.H.S.; Vijverberg, H.P.M. Toxicol. Appl. Pharmacol., 2002, 183, 153 .

[298] Shukla, G.S.; Singhal, R.L. Can. J. Physiol. Pharmacol., 1984, 62 1015.

[299] Vijverberg, H.P.M.; Oortgiesen, M.; Leinders, T.; Vankleef, R.G.D.M. Environ. Health Persp., 1994, 102, 153.

[300] Yamagami, K.; Nishimura, S.; Sorimachi, M. Brain Res., 1994, 646, 295.

[301] Tomsig, J.L.; Suszkiw, J.B. J. Neurochem., 1996, 66, 644.

[302] Kishimoto, T.; Liu, T.T.; Ninomiya, Y.; Takagi, H.; Yoshioka, T.; Ellis-Davies, G.C.R.; Miyashita, Y.; Kasai, H. J. Physiol., 2001 533,627

[303] Zuch, C.L.; O’Mara, D.J.; Cory-Slechta, D.A. Toxicol. Appl. Pharmacol., 1998, 150, 174.

[304] Manalis, R.S.; Cooper, G.P. Nature, 1973, 243, 354.

[305] Tomsig, J.L.; Suszkiw, J.B. Am. J. Physiol., 1993, 265, C1630.

[306] Bressler, J.P.; Belloniolivi, L.; Forman, S.; Goldstein, G.W. J. Neurosci. Res., 1996, 46, 678.

[307] Bouton, C.M.; Frelin, L.P.; Forde, C.E.; Godwin, A.H.; Pevsner, J J. Neurochem., 2001, 76, 1724

[308] Corcoran, J.J.; Kirshner, N. Cell Calcium, 1983, 4, 127.

[309] Shin, O.H.; Rhee, J.S.; Tang, J.; Sugita, S.; Rosenmund, C.; Südhof TC. Neuron, 2003, 37, 99.

[310] Kitazawa, M.; Anantharam, V.; Yang, Y.; Hirata, Y.; Kanthasamy, A.; Kanthasamy, A.G. Biochem. Pharmacol., 2005, 69, 133.

[311] Powis, D.A.; O'Brien, K.J.; Harrison, S.M.; Jarvie, P.E.; Dunkley, P.R. Cell Calcium, 1996, 19, 419.

[312] Drapeau, P.; Nachshen, D.A. J. Physiol., 1984, 348, 493.

[313] Alinovi, R.; Vettori, M.V.; Mutti, A.; Cavazzini, S.; Bacchini, A.; Bergamaschi, E. Neurotoxicology, 1996, 17, 743.

[314] Schaumburg, H.H. In Experimental and clinical neurotoxicology; Spencer; Schaumburg; Ludolph, Eds. Oxford University Press, New York, 2000; pp.1183-1189.

[315] Riegel, A.C.; French, E.D. Pharmacol. Biochem. Behav., 1999, 62 , 399.

[316] Meulenberg, C.J.W.; Vijverberg, H.P.M. Toxicology, 2003, 190, 243.

[317] Westerink, R.H.S.; Vijverberg, H.P.M. Neurosci. Lett., 2002, 326 81 .

[318] Tillar, R.; Shafer, T.J.; Woodward, J.J. Neurochem. Int., 2002, 41, 391.

[319] Larsen, K.E.; Fon, E.A.; Hastings, T.G.; Edwards, R.H.; Sulzer, D. J. Neurosci., 2002, 22, 8951 .

[320] Hanson, G.R.; Rau, K.S.; Fleckenstein, A.E. Neuropharmacol., 2004, 47 (Suppl 1), 92

[321] Chen, G.; Ewing, A.G. Brain Res., 1995, 701, 167.

[322] Russell, V.A. Behav. Brain Res., 2002, 130, 191.

[323] Carboni, E.; Silvagni, A. Neural Plast., 2004, 11, 77.

[324] Benoit-Marand, M.; Borrelli, E.; Gonon, F. J. Neurosci., 2001, 21 , 9134.

[325] Wu, Q.; Reith, M.E.A.; Walker, Q.D.; Kuhn, C.M.; Carroll, F.I.; Garris, P.A. J. Neurosci., 2002, 22, 6272. 